\title{
Dynamics of Rhodobacter capsulatus [2Fe-2S] Ferredoxin VI and Aquifex aeolicus Ferredoxin 5 via Nuclear Resonance Vibrational Spectroscopy (NRVS) and Resonance Raman Spectroscopy ${ }^{\dagger}$
}

\author{
Yuming Xiao, ${ }^{\ddagger}$ Ming-Liang Tan," Toshiko Ichiye, ${ }^{\prime \prime}$ Hongxin Wang, ${ }^{\S}$ Yisong Guo, ${ }^{\ddagger}$ Matt C. Smith, ${ }^{\ddagger}$ Jacques Meyer, ${ }^{\perp}$ \\ Wolfgang Sturhahn,, Ercan E. Alp, Jiyong Zhao, ${ }^{\#}$ Yoshitaka Yoda, ${ }^{\nabla}$ and Stephen P. Cramer*, ${ }^{*, \$}$ \\ Department of Applied Science, University of California, Davis, California 95616, Physical Biosciences Division, Lawrence \\ Berkeley National Laboratory, Berkeley, California 94720, Department of Chemistry, Georgetown University, \\ Washington, D.C. 20057, Département Réponse et Dynamique Cellulaires (UMR 5090 CEA-CNRS-UJF), CEA-Grenoble, \\ 38054 Grenoble, France, Advanced Photon Source, Argonne National Laboratory, Argonne, Illinois 60439, and JASRI, \\ SPring-8, 1-1-1 Kouto, Sayo-cho, Sayo-gun, Hyogo 679-5198, Japan
}

Received July 20, 2007; Revised Manuscript Received March 18, 2008

\begin{abstract}
We have used ${ }^{57} \mathrm{Fe}$ nuclear resonance vibrational spectroscopy (NRVS) to study the $\mathrm{Fe}_{2} \mathrm{~S}_{2}(\mathrm{Cys})_{4}$ sites in oxidized and reduced [2Fe-2S] ferredoxins from Rhodobacter capsulatus (Rc FdVI) and Aquifex aeolicus ( $\mathrm{A} a \mathrm{Fd} 5$ ). In the oxidized forms, nearly identical NRVS patterns are observed, with strong bands from $\mathrm{Fe}-\mathrm{S}$ stretching modes peaking around $335 \mathrm{~cm}^{-1}$, and additional features observed as high as the $\mathrm{B}_{2 \mathrm{u}}$ mode at $\sim 421 \mathrm{~cm}^{-1}$. Both forms of $R c \mathrm{FdVI}$ have also been investigated by resonance Raman (RR) spectroscopy. There is good correspondence between NRVS and Raman frequencies, but because of different selection rules, intensities vary dramatically between the two kinds of spectra. For example, the $\mathrm{B}_{3 \mathrm{u}}$ mode at $\sim 288 \mathrm{~cm}^{-1}$, attributed to an asymmetric combination of the two $\mathrm{FeS}_{4}$ breathing modes, is often the strongest resonance Raman feature. In contrast, it is nearly invisible in the NRVS, as there is almost no Fe motion in such $\mathrm{FeS}_{4}$ breathing. NRVS and RR analysis of isotope shifts with ${ }^{36} \mathrm{~S}$-substituted into bridging $\mathrm{S}^{2-}$ ions in $R c$ FdVI allowed quantitation of $\mathrm{S}^{2-}$ motion in different normal modes. We observed the symmetric $\mathrm{Fe}-\mathrm{Fe}$ stretching mode at $\sim 190 \mathrm{~cm}^{-1}$ in both NRVS and RR spectra. At still lower energies, the NRVS presents a complex envelope of bending, torsion, and protein modes, with a maximum at $78 \mathrm{~cm}^{-1}$. The ${ }^{57} \mathrm{Fe}$ partial vibrational densities of states (PVDOS) were interpreted by normalmode analysis with optimization of Urey-Bradley force fields. Progressively more complex $\mathrm{D}_{2 \mathrm{~h}} \mathrm{Fe}_{2} \mathrm{~S}_{2} \mathrm{~S}_{4}^{\prime}$, $\mathrm{C}_{2 \mathrm{~h}} \mathrm{Fe}_{2} \mathrm{~S}_{2}(\mathrm{SCC})_{4}$, and $\mathrm{C}_{1} \mathrm{Fe}_{2} \mathrm{~S}_{2}(\mathrm{Cys})_{4}$ models were optimized by comparison with the experimental spectra. After modification of the CHARMM22 all-atom force field by the addition of refined $\mathrm{Fe}-\mathrm{S}$ force constants, a simulation employing the complete protein structure was used to reproduce the PVDOS, with better results in the low frequency protein mode region. This process was then repeated for analysis of data on the reduced FdVI. Finally, the degree of collectivity was used to quantitate the delocalization of the dynamic properties of the redox-active Fe site. The NRVS technique demonstrates great promise for the observation and quantitative interpretation of the dynamical properties of $\mathrm{Fe}-\mathrm{S}$ proteins.
\end{abstract}

Plant- and mammalian-type [2Fe-2S] ferredoxins are generally small $(\sim 90-130$ amino acid residues) electrontransfer proteins with a single $\mathrm{Fe}_{2} \mathrm{~S}_{2}(\mathrm{~S} \text {-cys) })_{4}$ redox center ( 1 $-3)$. On the basis of their functional roles and structures, most of these proteins can be distributed into three main subgroups, namely, plant-type, mammalian-, vertebrate-, or

This work was funded by NIH Grants GM-65440 (to S.P.C.), EB001962 (to S.P.C.), and GM-45303 (to T.I.), and the DOE Office of Biological and Environmental Research (to S.P.C.). Use of the APS is supported by the DOE Office of Basic Energy Sciences, Office of Science. SPring- 8 is funded by JASRI.

* To Whom correspondence should be addressed. Tel: (530) 7520360. Fax: (530) 752-2444. E-mail: spjcramer@ucdavis.edu.

* University of California-Davis.

§ Lawrence Berkeley National Laboratory.

"Georgetown University.

${ }^{\perp}$ CEA-Grenoble.

\# Argonne National Laboratory.

${ }^{\nabla}$ SPring-8. hydroxylase-type, and Isc-type ferredoxins. In the first subgroup, in plants and algae, $[2 \mathrm{Fe}-2 \mathrm{~S}]$ ferredoxins mediate electron transfer between photosystem I and enzymes involved in NADPH production, sulfur and nitrogen assimilation, and nitrogen fixation (3). A better understanding of this process could have important biotechnological applications since electron transfer between ferredoxin and NADP via FNR has been shown to be the rate-limiting step in photosynthesis (4). In the second subgroup, [2Fe-2S] ferredoxins are involved in electron transfer to hydroxylases and oxygenases, in vertebrates, and also over a wide range of organisms including bacteria. Ferredoxins in the third subgroup play a role in $\mathrm{Fe}-\mathrm{S}$ cluster biosynthesis (5). As more sequence information has emerged, the relationships between $[2 \mathrm{Fe}-2 \mathrm{~S}]$ ferredoxins have been illuminated by dendrograms based on sequence similarity (Chart 1) (6). It should be noted that the second and third subgroups are overlapping, as some Isc-type Fds appear, on the basis of 
Chart 1: Dendrogram Based on Sequence Similarity between Different [2Fe-2S] Ferredoxins (Left) and VMD (10) Ribbon Representation for Oxidized $R c$ FdVI, Including [2Fe-2S] Cluster (Right)
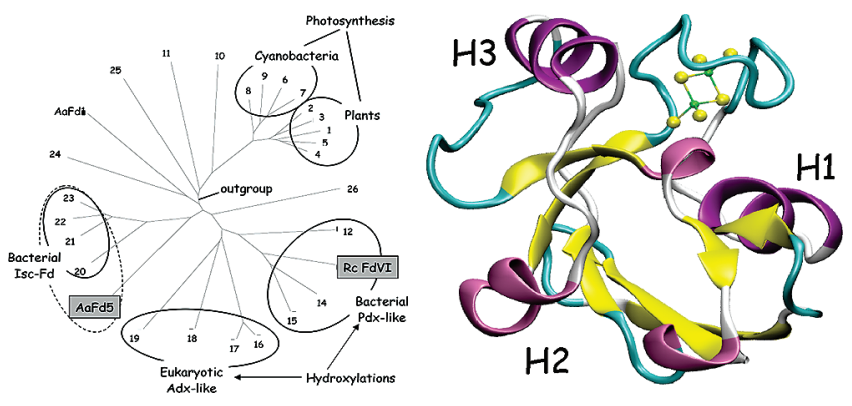

sequence similarity alone, to belong to the hydroxylationtype subgroup.

Rhodobacter capsulatus is a photosynthetic bacterium ( $\alpha$ Proteobacteria) with 6 distinct ferredoxin-encoding genes (7), all of which have been characterized genetically/ biochemically in the Jouanneau group $(7,8)$. Comparative genomics suggests that the sixth ferredoxin from this organism, $R c$ FdVI, is involved in the synthesis of iron-sulfur clusters (8), despite its seemingly closer overall sequence similarity to hydroxylation-type ferredoxins (see dendrogram in Chart 1). X-ray crystal structures for $R c$ FdVI, in the oxidized $(2.07 \AA$ resolution - 1E9M) and reduced forms $(2.00$ $\AA$ resolution - 1UWM) have recently been determined and compared (8). The structures for both forms (8) have been described as the same $\alpha \beta$ fold observed for other [2Fe-2S] ferredoxins ( $1-3)$, a twisted $\beta$-sheet composed of $5 \beta$-strands, flanked by one major $\alpha$-helix (H1 in Chart 1). Two minor helices (H2 and $\mathrm{H} 3$ in Chart 1) are present in a large hairpin referred to as the interaction domain. The [2Fe-2S] cluster lies 5-6 $\AA$ from the surface within a loop in the so-called core domain. Rc FdVI shares the Cys- $\mathrm{X}_{3}-\mathrm{Cys}-\mathrm{X}_{1}-\mathrm{Cys}_{-} \mathrm{X}_{2^{-}}$ Cys cluster-binding motif of other Fds known to be involved in $\mathrm{Fe}-\mathrm{S}$ cluster biosynthesis (8), where the second cysteine, which is not a cluster ligand, has been proposed as a binding site for $\mathrm{Fe}$ or $\mathrm{S}$ (9). $R c \mathrm{FdVI}$ shows strong sequence homology with $\mathrm{Pdx}(8)$, and in the crystal structures, an overall rms deviation of only $1 \AA$ was determined between main-chain $\mathrm{C}_{\alpha}$ atoms of $R c \mathrm{FdVI}$ and $\mathrm{Pdx}$ (8).

The oxidized $R c$ FdVI structure reveals a planar $\left[\mathrm{Fe}_{2} \mathrm{~S}_{2}\right]$ core and approximate $\mathrm{D}_{2 \mathrm{~h}}$ symmetry for the $\mathrm{Fe}_{2} \mathrm{~S}_{2}{ }_{2} \mathrm{~S}_{4}$ portion of the $\mathrm{Fe}_{2} \mathrm{~S}_{2} \mathrm{Cys}_{4}$ site (Chart 2). The orientations of the cysteine side chain carbons break this site symmetry. Conversion from oxidized to reduced forms results in a slight puckering of the $\mathrm{Fe}_{2} \mathrm{~S}_{2}$ core, as well as conformational changes at neighboring Met24 and Ala44 residues. The side chain of Met 24 rotates $180^{\circ}$, bringing the thioether $\mathrm{S}$ within $2.85 \AA$ of the cluster bridging S2. In addition, the Ala44 carbonyl $\mathrm{O}$ changes from pointing away from the cluster ("CO out" conformation) to pointing toward the cluster ("CO in" conformation). This conformational change brings it within $3.0 \AA$ of the Met70 S and $3.9 \AA$ of the cluster bridging S1.

Conformational changes have been observed upon reduction of other $[2 \mathrm{Fe}-2 \mathrm{~S}]$ ferredoxins, including the plant-type [2Fe-2S] Anabaena PCC7119 ferredoxin (Fd7119) (12), the vertebrate type adrenodoxin $(\mathrm{Adx})(13,14)$, and the vertebratetype putidaredoxin (Pdx) (15). In Fd7119, which also exhibits
Chart 2: Oxidized $R c$ FdVI $2 \mathrm{Fe}-2 \mathrm{~S}$ Site (Color) Using Crystal Structure Coordinates (1E9M) Compared to a Hypothetical $\mathrm{Fe}_{2} \mathrm{~S}_{2} \mathrm{~S}_{4}$ Model with $\mathrm{D}_{2 \mathrm{~h}}$ Symmetry (Gray) (Left) and Reduced $R c$ FdVI 2Fe-2S Site (Color) Using Crystal Structure Coordinates (1UWM) vs a Hypothetical $\mathrm{Fe}_{2} \mathrm{~S}_{2} \mathrm{~S}_{4}^{\prime}$ Model with $\mathrm{D}_{2 \mathrm{~h}}$ symmetry (Gray) (Right) ${ }^{a}$
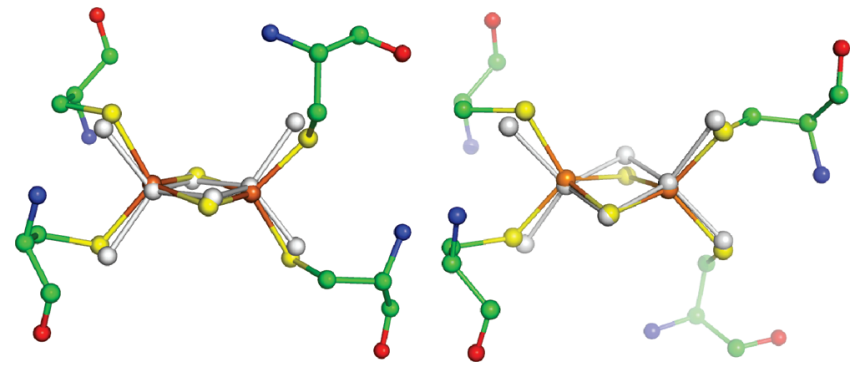

${ }^{a}$ Figures made with Pymol (11), and $\mathrm{H}$ atoms omitted for clarity.

a "CO out-CO in" isomerization for its Cys46 carbonyl group (12), molecular mechanics calculations find that the "CO in" form will rapidly convert to the "CO out" form upon reduction (16). With $\mathrm{Adx}$, it was proposed that the switch for detachment from adrenodoxin reductase (AdR) is the redox state of the $[2 \mathrm{Fe}-2 \mathrm{~S}]$ cluster (17), and molecular dynamics studies suggest that redox-induced changes in the flexibility of a 5 residue loop surrounding the iron-sulfur cluster could affect the binding and dissociation of Adx from AdR (17). In a similar vein, the reduced form of Pdx has a binding constant for cytochrome P-450 cam that is 2 orders of magnitude higher than that of the oxidized $\mathrm{Pdx}$ (18). This is a catalytically important effect that helps prevent product inhibition in the electron transfer reaction between $\mathrm{P}-450$ and Pdx (19). On the basis of paramagnetic effects on NMR spectra, residues Gly40 and Gly41 in the Pdx metal binding loop were proposed as potential hinges for conformational fluctuations (20), and additional evidence for this hypothesis came from Gly40 $\rightarrow \mathrm{N}$ site-directed mutagenesis (19).

For a variety of related $[2 \mathrm{Fe}-2 \mathrm{~S}] \mathrm{Fds}$, the frequencies of stretching modes are available from resonance Raman spectroscopy. In the oxidized forms, the Raman spectra generally exhibit 6 or 7 resolved peaks between 280 and $430 \mathrm{~cm}^{-1}(6,21-23)$, which correspond to $8 \mathrm{Fe}-\mathrm{S}$ stretching modes (2 of which are unresolved) in $\mathrm{D}_{2 \mathrm{~h}}$ symmetry for a $\mathrm{Fe}_{2} \mathrm{~S}_{2}{ }_{2} \mathrm{~S}_{4}$ core (24). Spiro and co-workers used a Urey-Bradley force field with an $\mathrm{Fe}_{2} \mathrm{~S}_{2}{ }_{2}\left(\mathrm{~S}^{\mathrm{t} C C}\right)_{4}$ model to successfully reproduce most of the $\mathrm{Fe}-\mathrm{S}$ stretching frequencies. As with rubredoxin $(25-27)$, they emphasized the importance of $\mathrm{Fe}-\mathrm{S}-\mathrm{C}-\mathrm{C}$ dihedral angles for coupling $\mathrm{Fe}-\mathrm{S}$ stretching with $\mathrm{S}-\mathrm{C}-\mathrm{C}$ bending (24) and proposed that the $\mathrm{Fe}-\mathrm{S}^{\mathrm{t}}$ stretching mode frequencies can be used as diagnostics for the local conformation. In some cases, the predictions have been quite successful, while in other cases the correlation is less apparent (Table S1). For example, Han and co-workers predicted dihedral angles of $105^{\circ}$ for $S$. platensis ferredoxin (22), and the most recent crystal structure (PDB entry 4FXC) reveals values of $120,123,100$, and $100^{\circ}(28)$. For comparison, $\mathrm{Fu}$ and co-workers used the $319 \mathrm{~cm}^{-1}$ frequency of the " $\mathrm{B}_{2} \mathrm{Fe}-\mathrm{S}^{\mathrm{t}}$ " stretching mode in putidaredoxin to predict dihedral $\mathrm{Fe}(\mathrm{III})-\mathrm{S}-\mathrm{C}_{\beta}-\mathrm{C}_{\alpha}$ angles close to $90^{\circ}$ or $270^{\circ}$ for the cysteines ligated to the Fe(III) site (21). However, in the reduced $\mathrm{Pdx}$ structures that have recently become available (albeit for mutant proteins), the $\mathrm{Fe}(\mathrm{III})-\mathrm{S}-\mathrm{C}_{\beta}-\mathrm{C}_{\alpha}$ dihedral 
angles are at an average of $124^{\circ}(29)$. Similarly, the increased separation between the $\mathrm{B}_{3 \mathrm{u}}{ }$ mode and $\mathrm{A}_{\mathrm{g}}^{\mathrm{t}}, \mathrm{B}_{2 \mathrm{~g}}$, and $\mathrm{B}_{3 \mathrm{u}}^{\mathrm{b}}$ modes has been used to argue for more planar $\mathrm{Fe}(\mathrm{III})-\mathrm{S}$ $\mathrm{C}_{\beta}-\mathrm{C}_{\alpha}$ dihedral angles in T. vaginalis ferredoxin compared to Pdx (30). Yet, the subsequent crystal structure of $T$. vaginalis ferredoxin (PDB entry $1 \mathrm{~L} 5 \mathrm{P}$ ) revealed $\mathrm{Fe}(\mathrm{III})-\mathrm{S}$ $\mathrm{C}_{\beta}-\mathrm{C}_{\alpha}$ dihedral angles at an average of $113^{\circ}(31)$, compared to the $120^{\circ}$ average found in $\mathrm{Pdx}$ (29).

Rotsaert et al. observed ${ }^{15} \mathrm{~N}$ isotope shifts for modes at 282, 340, and $357 \mathrm{~cm}^{-1}$ in the resonance Raman of Anabaena $\mathrm{Fd}$, indicating coupling of $\mathrm{C}_{\beta}-\mathrm{C}_{\alpha}-\mathrm{N}$ deformation to $\mathrm{Fe}-\mathrm{S}^{\mathrm{t}}$ stretching (32). Furthermore, since the Fe-S- $\mathrm{C}_{\beta}-\mathrm{C}_{\alpha}$ dihedral angles in this protein are between $90^{\circ}$ and $120^{\circ}(33)$, they concluded that "some kinematic coupling is feasible among bonded atoms that are not coplanar" (32). The degree of coupling between $\mathrm{Fe}-\mathrm{S}$ stretching and deformations of the polypeptide backbone has also been debated for [2Fe-2S] Rieske proteins (34).

For [2Fe-2S] model compounds (24), other Raman bands have been seen below $200 \mathrm{~cm}^{-1}$, and these features have been assigned as a mixture of $\mathrm{Fe}-\mathrm{S}-\mathrm{C}$ and $\mathrm{S}-\mathrm{Fe}-\mathrm{S}$ bending modes. However, since only a few modes of those expected for even the simplest $\mathrm{Fe}_{2} \mathrm{~S}_{2}{ }_{2}\left(\mathrm{~S}^{\mathrm{t}} \mathrm{CC}\right)_{4}$ model are observed in Raman spectra, the bend and torsion components of $\mathrm{Fe}-\mathrm{S}$ cluster empirical force fields are generally not well defined. The lower frequency cluster modes may exhibit stronger coupling to protein deformation modes.

The dynamical characteristics of the oxidized and reduced metal sites play an important role in the properties of $\mathrm{Fe}-\mathrm{S}$ clusters and their associated proteins. Redox-dependent changes in metalloprotein structure have been known for several decades $(35,36)$. Apart from their significance with [2Fe-2S] Fds and their partners (17-19), such conformational changes seem to play a role in electron transfer in photosynthesis (37), in the binding and release of the nitrogenase Fe protein to its $\mathrm{MoFe}$ protein partner (38), and in the many complex events requiring $\mathrm{Fe}-\mathrm{S}$ proteins (39) including nitrogenase (40) and hydrogenase (41). Considering the number of predictions that have been made and the lingering issues about the normal mode compositions, it is clear that more information about $[2 \mathrm{Fe}-2 \mathrm{~S}]$ cluster dynamics would be useful for any predictions about structure and function in $\mathrm{Fe}-\mathrm{S}$ proteins. To obtain such information, we have examined $R c$ FdVI by a combination of resonance Raman spectroscopy and nuclear resonance vibrational spectroscopy (NRVS), interpreted by normal mode calculations with a modified CHARMM force field.

NRVS is rapidly becoming a popular technique for probing the dynamics of $\mathrm{Fe}$ in metalloproteins $(42,43)$. This measurement involves scanning an extremely monochromatic $\mathrm{X}$-ray beam through a nuclear resonance. Apart from the zero phonon recoil-free Mössbauer resonance, there are transitions that correspond to nuclear excitation plus creation (Stokes) or annihilation (anti-Stokes) of phonons. The NRVS intensity for a given normal mode is proportional to the motion of the resonant nucleus $j$ (in this case ${ }^{57} \mathrm{Fe}$ ) along the direction of the incident X-ray beam $(43,44)$. For a randomly oriented sample, a NRVS transition for normal mode $\alpha$ contributes a fraction $\varphi_{\alpha}$ to the normalized excitation probability $S\left({ }^{-} v\right)$ that is directly proportional to the Fe mode composition factor $e_{j \alpha}^{2}$ and inversely proportional to $\bar{v}_{\alpha}(44,45)$ :

$$
\varphi_{\alpha}=\frac{1}{3} \bar{v}_{R} \bar{v}_{\alpha}^{2} e_{j \alpha}^{2}\left(\bar{n}_{\alpha}+1\right) f
$$

In the above equation, $\bar{v}_{\alpha}$ is the difference between the photon energy and the recoil-free nuclear resonance energy in wave numbers, $\bar{v}_{R}$ is the recoil energy $\left(\sim 16 \mathrm{~cm}^{-1}\right)$, $\bar{n}_{\alpha}=\left[\exp \left(h c \bar{v}_{\alpha} / k_{B} T\right)-1\right]^{-1}$ is the thermal occupation factor for a mode of frequency $\bar{v}_{\alpha}$ at temperature $T$ (44), and the recoilless fraction $f$ depends on $\left\langle\mathrm{x}_{\mathrm{Fe}}{ }^{2}\right\rangle$, the mean square fluctuation of the Fe nucleus along the beam direction, via $f=\exp \left(-k^{2}\left\langle\mathrm{x}_{\mathrm{Fe}}^{2}\right\rangle\right)$. It is also useful to define an ${ }^{57} \mathrm{Fe}$-centered partial vibrational density of states (PVDOS), $D_{F e}(\bar{v})$, using a line shape function $\mathscr{f}\left(\bar{v}-\bar{v}_{\alpha}\right)(44,46)$ :

$$
D_{F e}(\bar{v})=\sum_{\alpha} e_{F e, \alpha}^{2} \mathscr{f}\left(\bar{v}-\bar{v}_{\alpha}\right)
$$

The ${ }^{57} \mathrm{Fe}$ PVDOS can be extracted from the raw NRVS using the PHOENIX software package (47), and the Fe mode composition factor $e^{2} \mathrm{Fe}, \alpha$ for a given eigenvector can be calculated from a normal-mode analysis via $(44,48)$ :

$$
e_{F e, \alpha}^{2}=\frac{m_{F e} r_{F e, \alpha}^{2}}{\sum_{i} m_{i} r_{i \alpha}^{2}}
$$

where $m_{\mathrm{i}}$ and $r_{\mathrm{i \alpha}}{ }^{2}$ are the mass of atom $i$ and its mean square motion in mode $\alpha$, respectively.

In this article, we report the ${ }^{57} \mathrm{Fe}$ NRVS for oxidized and reduced forms of ${ }^{57} \mathrm{Fe}$-enriched $R c$ FdVI, both with natural abundance sulfur as well as with ${ }^{36} \mathrm{~S}$ in the bridging sulfide positions. NRVS data for ${ }^{57} \mathrm{Fe}$-enriched oxidized and reduced forms of another [2Fe-2S] ferredoxin, Aquifex aeolicus $\mathrm{Fd} 5$, are included for comparison. Resonance Raman spectra for all of the $R c$ FdVI and $A a \mathrm{Fd} 5$ samples are also presented. Normal mode calculations on models of increasing complexity are used to reproduce and interpret the experimental data. By combining NRVS and Raman spectra, we were able to refine Urey-Bradley force fields for both oxidized and 1-electron reduced sites. The NRVS data also reveal low frequency modes not evident in the Raman spectra. The results are compared with previous Raman and molecular mechanics analyses of [2Fe-2S] ferredoxins.

\section{EXPERIMENTAL PROCEDURES}

Protein Purification and Sample Preparation. Aquifex aeolicus $\mathrm{Fd} 5$ ( $\mathrm{A} a \mathrm{Fd} 5$ ) was produced in Escherichia coli and purified as described (6), but with ${ }^{57} \mathrm{Fe}$ in the growth medium. For that purpose, metallic ${ }^{57} \mathrm{Fe}$ was dissolved in a mixture of concentrated $\mathrm{HCl}$ and $\mathrm{HNO}_{3}$ and added to the medium for a final concentration of $1 \mathrm{mg} / \mathrm{L}$. Rhodobacter capsulatus FdVI ( $R c$ FdVI) was produced in E. coli as described (7), but the medium was as indicated above for $A a \mathrm{Fd} 5$. Rc FdVI was purified as described above for $A a \mathrm{Fd} 5$, except that the heat treatment was omitted. With these procedures, both $A a$ Fd5 and $R c$ FdVI were obtained directly as ${ }^{57} \mathrm{Fe}$-enriched proteins. The A415/A276 absorption ratios of purified $A a$ Fd5 and $R c$ FdVI were 0.70 and 0.54 , respectively.

The preparation of ${ }^{36} \mathrm{~S}$-enriched $R c$ FdVI was performed as described for ${ }^{34} \mathrm{~S}$-substitution in spinach ferredoxin (49). A critical step was the implementation of $\mathrm{HCl}(0.5 \mathrm{~N})$ and anaerobic conditions for denaturation of the holoprotein. For the reconstitution, elemental ${ }^{36} \mathrm{~S}$ was reduced to the $\mathrm{S}^{2-}$ 
oxidation level by heating in a dihydrogen atmosphere, and ${ }^{57} \mathrm{Fe}$ was implemented in the reconstitution reaction. The UV-visible absorption spectrum of the reconstituted Fd was identical to the spectrum of the native protein, except for a slightly lower A414/A278 ratio ( 0.50 versus 0.54$)$. A reduced sample was prepared by dithionite reduction in an anaerobic $\mathrm{N}_{2}$-containing glovebox. Both of the ${ }^{36} \mathrm{~S}$-enriched $R c$ FdVI samples have ${ }^{36} \mathrm{~S}$ in the $[2 \mathrm{Fe}-2 \mathrm{~S}]$ cluster bridging positions, and natural abundance sulfur in the cysteine thiolates.

Nuclear Resonance Vibrational Spectroscopy. ${ }^{57} \mathrm{Fe}$ NRVS spectra were recorded using published procedures (43) on multiple occasions at Beamline 3-ID at the Advanced Photon Source (APS) (50) and Beamline 9-XU at SPring-8, Japan (51). Beamline 3-ID provided $\sim 2.5 \times 10^{9}$ photons/s in 1 meV bandwidth at $14.4125 \mathrm{keV}$ in a $1 \mathrm{~mm}$ (vertical) $\times 3$ $\mathrm{mm}$ (horizontal) spot, using a water-cooled diamond $(1,1,1)$ double crystal monochromator with $1.1 \mathrm{eV}$ bandpass, followed by separate $\mathrm{Si}(4,0,0)$ and $\mathrm{Si}(10,6,4)$ channel-cut crystals in a symmetric geometry. The flux at SPring- 8 was $\sim 3 \times 10^{9}$ in a $1.1 \mathrm{meV}$ bandwidth, using a $\mathrm{LN}_{2}$-cooled $\mathrm{Si}(1,1,1)$ double crystal monochromator followed by asymmetrically cut $\mathrm{Ge}(4,2,2)$ and two $\operatorname{Si}(9,7,5)$ crystals. For NRVS measurements, protein samples were loaded into 3 $\times 7 \times 1 \mathrm{~mm}^{3}$ (interior dimensions) Lucite cuvettes. During these measurements, samples were maintained at low temperatures using liquid $\mathrm{He}$ cryostats. Temperatures were calculated using the ratio of anti-Stokes to Stokes intensity according to: $S(-E)=S(E) \exp (-E / k T)$. Spectra were recorded between -20 and $80 \mathrm{meV}$ in $0.25 \mathrm{meV}$ steps at APS and $0.3 \mathrm{meV}$ steps at SPring-8. Nuclear fluorescence and $\mathrm{Fe} \mathrm{K}$ fluorescence (from internal conversion) were recorded with a single $1 \mathrm{~cm}^{2}$ square avalanche photodiode (APD) at the APS and with an APD array at SPring-8. Each scan took about $40 \mathrm{~min}$, and all scans were added and normalized to the intensity of the incident beam.

Raman Spectroscopy. Resonance Raman spectra were recorded in backscattering geometry from drops of $R c \mathrm{FdVI}$ and $\mathrm{A} a \mathrm{Fd} 5$ solutions frozen on a Au-plated $\mathrm{Cu}$ coldfinger inside an Oxford Optistat-DN LN2 cryostat at $77 \mathrm{~K}$. The excitation source was a Coherent Innova- $2 \mathrm{Ar}^{+} / \mathrm{Kr}^{+}$laser, using a power of $\sim 35 \mathrm{~mW}$. No sample radiation damage was observed. The spectra were recorded at $\sim 6 \mathrm{~cm}^{-1}$ resolution with a Spex model 1877 triple spectrograph, using a cooled Spectrum One 594 CCD detector. Each spectrum represents $\sim 8-16 \mathrm{~h}$ of measurement. The spectra were calibrated versus $218 \mathrm{~cm}^{-1}$ and $314 \mathrm{~cm}^{-1}$ peaks in a room temperature $\mathrm{CCl}_{4}$ sample.

Normal Mode Calculations. The crystal structures for oxidized and reduced $R c$ FdVI (1E9M and 1UWM, respectively) were used as starting points (8), and symmetrized models were derived from these coordinates using the program Atoms $(52,53)$. The local site normal mode calculations were carried out with a Urey-Bradley force field using a modification of the program Vibratz $(52,53)$. A QR algorithm was used for finding eigenvectors (54). The resulting normal modes were broadened by a convolution with a $10 \mathrm{~cm}^{-1}$ fwhm Voigt profile. The parameters of the force field were optimized by minimizing the residual $\Delta$ defined by:

$$
\Delta=\frac{1}{N} \sum_{i}^{N}\left(D_{o b s}\left(v_{i}\right)-D_{\text {calc }}\left(v_{i}\right)\right)^{2}+\frac{c}{M} \sum_{j}^{M}\left(v_{j}^{o b s}-v_{j}^{c a l c}\right)^{2}(4)
$$

In the above equation, $D_{\text {obs }}\left(v_{\mathrm{i}}\right)$ and $D_{\text {calc }}\left(v_{\mathrm{i}}\right)$ are, respectively, the observed and calculated ${ }^{57} \mathrm{Fe}$ PVOS at frequency $v_{\mathrm{i}}, N$ is the number of NRVS data points, $v_{\mathrm{j}}^{\text {obs }}$ and $v_{\mathrm{j}}^{\text {calc }}$ are, respectively, the observed and calculated Raman frequencies, $M$ is the number of observed Raman frequencies, and $c$ is a weighting factor to adjust the relative importance of NRVS and Raman data sets. Initially, the weighting factor used was 1000. This essentially forced the optimization to match the Raman frequencies as well as possible, and within that constraint, to reproduce the NRVS. Subsequently, we found that if the PVDOS were in units of $\mathrm{eV}^{-1}$ and the Raman frequencies were in units of $\mathrm{cm}^{-1}$, then a weighting factor of $\sim 1$ yielded better fits to the NRVS data, while still matching the Raman constraints reasonably well.

For the full protein calculations, $\mathrm{H}$ atom positions were built using the HBUILD facility of CHARMM 33 (55). The systems contain 1586 protein atoms and 56 crystal water molecules (142 waters for reduced protein). The force field parameters consisted of the CHARMM22 all-atom parameters (55) plus additional parameters for the $\mathrm{Fe}_{2} \mathrm{~S}_{6}$ assembly as initially obtained from the local site optimization. To obtain a structure for the full protein normal mode calculation, it was necessary to refine the crystal structures (1E9 M and (UWM) to a minimal energy conformation. Constraints were introduced during the minimizations that led to a minimal energy structure close to the crystal structure, and a mass-weighted atomic harmonic potential was applied to each heavy atom. The systems were energy-minimized by 1000 steps of steepest descent method followed by successive sets of Adopted Basis Newton-Raphson (ABNR) minimizations (500 steps each) with the constraints reduced and the reference structure updated for each set; the final constraint constant was $0.05 \mathrm{kcal} / \mathrm{mol} / \AA^{2}$ per atomic mass. The normal mode calculations were then performed without constraints using the VIBRan module in the CHARMM 33 program (55). For comparison with the experimental spectra, Gaussian functions were calculated centered around each $\omega_{\alpha}$, the frequency of mode $\alpha$, using an $8 \mathrm{~cm}^{-1}$ fwhm and amplitude proportional to $e_{j \alpha}^{2}$. The ${ }^{57} \mathrm{Fe}$ PVDOS was then obtained by summing these Gaussian functions over all modes.

Degree of Collectivity Calculations. The degree of collectivity $\kappa$ for normal mode $\alpha$, first proposed by Bruschweiler (56), was calculated by the equation given by Tama and Sanejouand (57), except that the cluster Fe and S atoms were included in the summation along with all non-hydrogen protein atoms:

$$
\kappa=\frac{1}{N} \exp \left(-\sum^{N} a r_{i \alpha}^{2} \log a r_{i \alpha}^{2}\right)
$$

where $a$ is a normalization factor chosen so that $\sum_{i}^{N} a r_{i \alpha}^{2}=1$.

\section{RESULTS AND DISCUSSION}

Resonance Raman Spectra. We discuss the resonance Raman data first, since there is a wealth of similar spectra available for other [2Fe-2S] ferredoxins, including spinach (21, 58), Anabaena, and Porphyra umbilicalis Fds (32), bovine (22) and human (23) Adxs, Aa Fd1 (23) and Fd5 (6), Pdx (21), and [2Fe-2S] sites in hydrogenases (59). When excited at $514.5 \mathrm{~nm}$, the spectrum for Rc FdVI exhibits 


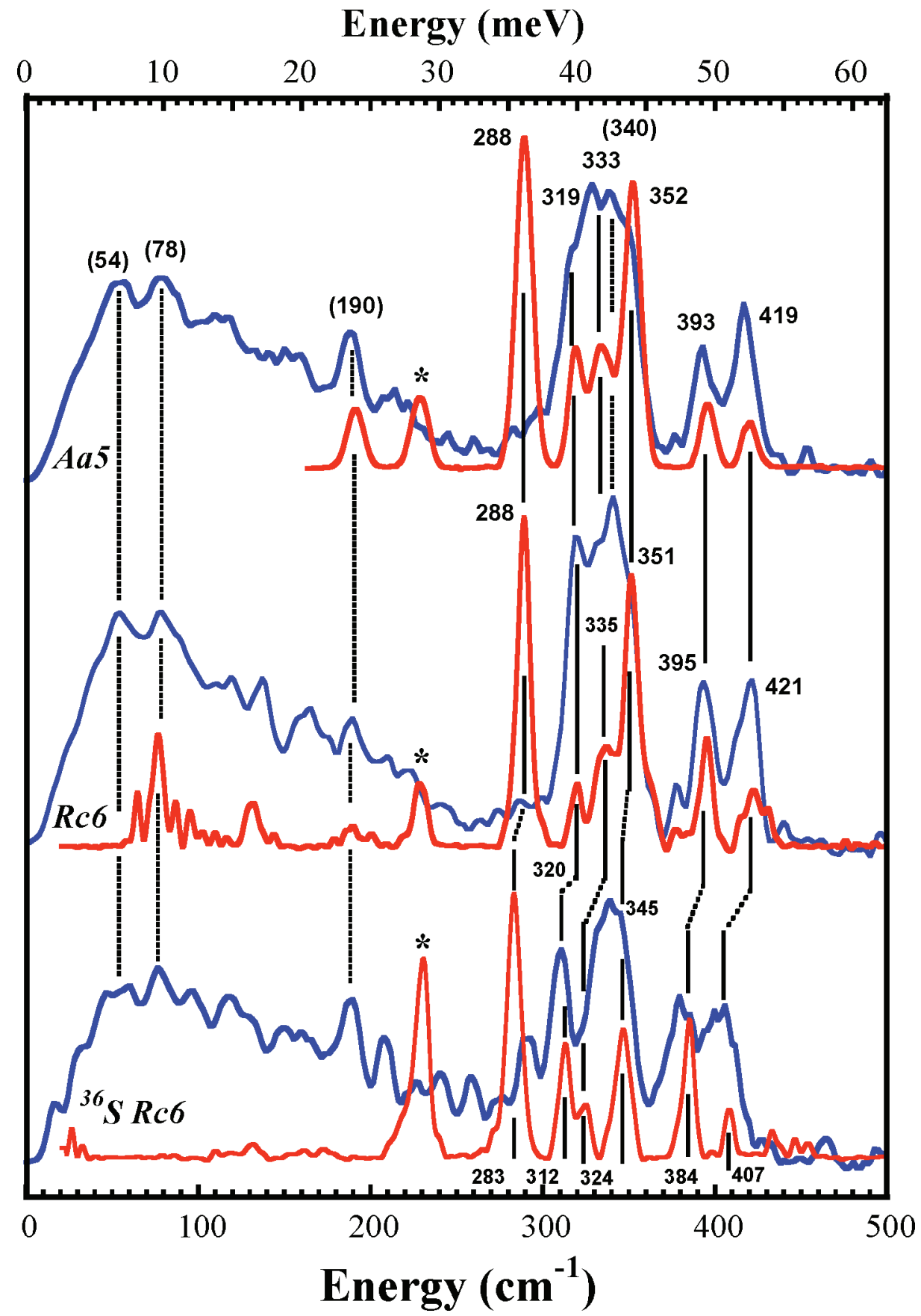

FIGURE 1: Top to bottom: resonance Raman spectra, using excitation at $515 \mathrm{~nm}$ (red line), compared with ${ }^{57} \mathrm{Fe}$ PVDOS (blue line) for oxidized, ${ }^{57} \mathrm{Fe}$-enriched (a) $A a \mathrm{Fd} 5$, (b) RcFdVI, and (c) ${ }^{36} \mathrm{~S}^{\mathrm{b}}$-substituted $R c$ FdVI. * Marks ice band in Raman spectra. Dashed vertical lines highlight common PVDOS features between spectra; solid lines mark Raman peak positions. Numbers in parentheses refer to PVDOS peaks; the remaining values are Raman peak positions.

6 distinct bands in the $\mathrm{Fe}-\mathrm{S}$ stretching region between 280 and $420 \mathrm{~cm}^{-1}$ (Figure 1), with relative intensities quite similar to those for $A a \operatorname{Fd} 5$ (6) (and Figure 1) and Pdx (21). The strongest features in the natural abundance $S$ resonance Raman of the former two proteins are at $288 \mathrm{~cm}^{-1}$, assigned as the $\mathrm{B}_{3 \mathrm{u}}{ }^{\mathrm{t}}$ asymmetric $\mathrm{Fe}-\mathrm{S}^{\mathrm{t}}$ stretching mode, and at 351 $\mathrm{cm}^{-1}$, assigned as the $\mathrm{B}_{3 \mathrm{u}}{ }^{\mathrm{b}}$ asymmetric $\mathrm{Fe}-\mathrm{S}^{\mathrm{b}}$ stretching mode. Despite the terminal and bridging labels (21), for both features we observe $\sim 5-7 \mathrm{~cm}^{-1}$ shifts with ${ }^{36} \mathrm{~S}$ substitution in $R c$ FdVI. Given that we are using ${ }^{36} \mathrm{~S}$ instead of ${ }^{34} \mathrm{~S}$, these shifts agree nicely with the $3.3 \mathrm{~cm}^{-1}$ shifts seen for these modes after ${ }^{34} \mathrm{~S}$ substitution in $\mathrm{Pdx}(21)$. A simple $\mathrm{Fe}-\mathrm{S}$ harmonic oscillator would shift $\sim 3.5 \%$ between ${ }^{32} \mathrm{~S}$ and ${ }^{36} \mathrm{~S}$, or $\sim 10-12 \mathrm{~cm}^{-1}$ shift in this region. The $\sim 2 \%$ shifts observed for these features indicate that in $R c$ FdVI, as in $\mathrm{Pdx}$, there is substantial mixing of bridging $\mathrm{S}$ motion with terminal $\mathrm{S}$ (and/or other atom) motion in these modes.

Four other predominantly $\mathrm{Fe}-\mathrm{S}$ stretching peaks are clear in the Raman data. The highest frequency ${ }^{36} \mathrm{~S}$-sensitive mode is at $421 \mathrm{~cm}^{-1}$ and corresponds to the $426 \mathrm{~cm}^{-1}$ band in $\mathrm{Pdx}$ (all of our spectra refer to ${ }^{57} \mathrm{Fe}$ proteins). The latter has been assigned as a $\mathrm{B}_{2 \mathrm{u}}{ }^{\mathrm{b}}$ asymmetric $\mathrm{Fe}-\mathrm{S}^{\mathrm{b}}$ stretching mode in idealized $\mathrm{D}_{2 \mathrm{~h}}$ symmetry for the $\mathrm{Fe}_{2} \mathrm{~S}_{2}{ }_{2} \mathrm{~S}_{4}$ core (21), with the symmetry labels defined by placing the $x$-axis along the $\mathrm{Fe}-\mathrm{Fe}$ vector and the $z$-axis normal to the $\mathrm{Fe}_{2} \mathrm{~S}_{2}{ }^{\mathrm{b}}$ plane. (Some earlier papers (60) used different $x$-axes, resulting in the permutation of the symmetry labels.) We observe a substantial $\left(\sim 14 \mathrm{~cm}^{-1}\right)$ shift with ${ }^{36} \mathrm{~S}$ substitution into the 
Table 1: Mode Assignments and Calculated and Observed $\mathrm{Fe}-\mathrm{S}$ Stretching Frequencies and ${ }^{36} \mathrm{~S}$ Isotope Shifts for Oxidized $R c$ FdVI Using the $\mathrm{C}_{2} \mathrm{~h}$ $\mathrm{Fe}_{2} \mathrm{~S}_{2}(\mathrm{SCC})_{4}$ Model

\begin{tabular}{|c|c|c|c|c|c|c|c|c|c|c|c|}
\hline \multicolumn{3}{|c|}{ mode label } & \multicolumn{2}{|c|}{$\mathrm{Pdx},{ }^{b}$ Ado, ${ }^{c}$ and $\operatorname{spinach}^{d}$ Raman } & \multicolumn{2}{|c|}{${ }^{57} \mathrm{Fe} R c$ FdVI Raman ${ }^{e}$} & \multicolumn{2}{|c|}{${ }^{57} \mathrm{Fe} R c$ FdVI NRVS ${ }^{e}$} & \multicolumn{3}{|c|}{ calculated values } \\
\hline$D_{2 h}$ & $\mathrm{C}_{2 \mathrm{~h}}$ & $\mathrm{C}_{2 \mathrm{v}}$ & $v\left(\mathrm{~cm}^{-1}\right)$ & $\Delta v{ }^{34} \mathrm{~S}\left(\mathrm{~cm}^{-1}\right)$ & $v\left(\mathrm{~cm}^{-1}\right)$ & $\Delta v{ }^{36} \mathrm{~S}\left(\mathrm{~cm}^{-1}\right)$ & $v\left(\mathrm{~cm}^{-1}\right)$ & $\Delta v{ }^{36} \mathrm{~S}\left(\mathrm{~cm}^{-1}\right)$ & $v\left(\mathrm{~cm}^{-1}\right)$ & $\Delta v^{36} \mathrm{~S}\left(\mathrm{~cm}^{-1}\right)$ & $e_{\mathrm{Fe}}^{2}$ \\
\hline $\mathrm{B}_{2 \mathrm{u}}^{\mathrm{b}}$ & $\mathrm{B}_{\mathrm{u}}^{\mathrm{b}}$ & $\mathrm{B}_{1}$ & 426421428 & 6.16 .34 .5 & 421 & 14 & 421 & 16 & 419.1 & 14.5 & 0.373 \\
\hline $\mathrm{B}_{1 \mathrm{u}}{ }^{\mathrm{t}}$ & $\mathrm{A}_{\mathrm{u}}{ }^{\mathrm{t}}$ & $\mathrm{B}_{2}$ & 344341355 & 0.80 .81 .5 & $340^{a}$ & & 341 & $\sim 0$ & 335.0 & 0 & 0.386 \\
\hline $\mathrm{B}_{2 \mathrm{~g}} \mathrm{t}^{\mathrm{t}}$ & $\mathrm{Bg}^{\mathrm{t}}$ & $\mathrm{B}_{2}$ & 344341340 & 0.80 .82 .5 & $340^{a}$ & & 341 & $\sim 0$ & 335.0 & 0 & 0.386 \\
\hline $\mathrm{Ag}_{\mathrm{g}}^{\mathrm{t}}$ & $\mathrm{A}_{\mathrm{g}}{ }^{\mathrm{t}}$ & $\mathrm{A}_{1}$ & 338329340 & 2.71 .52 .5 & $329^{a}$ & $5^{a}$ & & & 316.7 & 3.6 & 0.041 \\
\hline
\end{tabular}

${ }^{a}$ Approximate value based on decomposition of broad feature at $335 \mathrm{~cm}^{-1}$ (by analogy to Adx) and shifts in ${ }^{36} \mathrm{~S}$ spectrum; sh $=$ unresolved shoulder. ${ }^{b} \operatorname{Ref} 21 .{ }^{c} \operatorname{Ref} 22 .{ }^{d} \operatorname{Ref} 58 .{ }^{e}$ This work.

bridging $\mathrm{S}$ position (Table 1), consistent with a relatively pure $\mathrm{Fe}-\mathrm{S}^{\mathrm{b}}$ stretching assignment. At slightly lower energy, we see the symmetric $\mathrm{A}_{\mathrm{g}}{ }^{\mathrm{b}} \mathrm{Fe}-\mathrm{S}^{\mathrm{b}}$ stretching mode at 395 $\mathrm{cm}^{-1}$. For this mode, the $\sim 11 \mathrm{~cm}^{-1}$ shift with ${ }^{36} \mathrm{~S}$ substitution is also consistent with a large component of bridging $\mathrm{S}$ motion. Two other clear maxima in the natural abundance $\mathrm{S}$ spectrum are at $320 \mathrm{~cm}^{-1}$ and at $\sim 335 \mathrm{~cm}^{-1}$. The $320 \mathrm{~cm}^{-1}$ band appears to shift to $312 \mathrm{~cm}^{-1}$ with ${ }^{36} \mathrm{~S}$ substitution, consistent with $\mathrm{B}_{1 \mathrm{~g}}{ }^{\mathrm{b}}$ symmetric $\mathrm{Fe}-\mathrm{S}^{\mathrm{b}}$ stretching assignment. However, the apparent $10-11 \mathrm{~cm}^{-1}$ shift of the 335 $\mathrm{cm}^{-1}$ peak to $324 \mathrm{~cm}^{-1}$ seems large given the $\mathrm{A}_{\mathrm{g}}{ }^{\mathrm{t}}$ and $\mathrm{B}_{1 \mathrm{u}}{ }^{\mathrm{t}}$ \% $\mathrm{B}_{2 \mathrm{~g}}{ }^{\mathrm{t}} \mathrm{Fe}-\mathrm{S}^{\mathrm{t}}$ previous stretching assignments for this region.

On closer inspection, the band at $\sim 335 \mathrm{~cm}^{-1}$ is seen to be significantly broader than the other spectral features. With the closely related Adx protein, by using $406.9 \mathrm{~nm}$ excitation, Han and co-workers resolved two peaks at 329 and $341 \mathrm{~cm}^{-1}$ in this region (22). In another similar protein, Pdx, a peak at $344 \mathrm{~cm}^{-1}$ with $406.9 \mathrm{~nm}$ excitation was replaced by a 338 $\mathrm{cm}^{-1}$ peak with $457.9 \mathrm{~nm}$ incident radiation (21). Thus, a plausible interpretation of our $R c$ FdVI Raman spectrum is that there are (at least) 2 unresolved modes in the $\sim 335 \mathrm{~cm}^{-1}$ region. By analogy with $\mathrm{Adx}$ and $\mathrm{Pdx}$, we assume that one of these peaks has a $3-5 \mathrm{~cm}^{-1}{ }^{36} \mathrm{~S}$ isotope shift to $324 \mathrm{~cm}^{-1}$, while the other feature is assumed to have a small or negligible shift (Table 1).

Below the ice band at $230 \mathrm{~cm}^{-1}$, a number of weak features corresponding to bending and torsional modes can be seen. In particular, a band at $\sim 190 \mathrm{~cm}^{-1}$ is apparent, both for $R c$ FdVI and especially for $A a \mathrm{Fd} 5$. In model compound studies, Han and co-workers assigned similar bands at $197-210 \mathrm{~cm}^{-1}$ as $\mathrm{A}_{\mathrm{g}} \mathrm{Fe}-\mathrm{Fe}$ stretching modes (24). At lower energies, we observed a feature at $131 \mathrm{~cm}^{-1}$, which lacks a significant ${ }^{36} \mathrm{~S}$ isotope shift and matches a band reported two decades ago by Meyer, Moulis, and Lutz (58). Finally, there appears to be a real band at $77 \mathrm{~cm}^{-1}$ in the natural abundance S Rc FdVI Raman spectrum, but we were not able to observe this feature in the less concentrated ${ }^{36} \mathrm{~S}$-enriched $R c$ FdVI sample.

Resonance Raman spectra for reduced $R c$ FDVI are shown in Figure 2. These data strongly resemble previously published spectra for reduced Pdx (21). In contrast with the oxidized FdVI spectrum, only 4 clear ${ }^{36} \mathrm{~S}$-sensitive bands are observed, at $402,381,310$, and $276 \mathrm{~cm}^{-1}$ in the sample with natural abundance $\mathrm{S}$. The band at $310 \mathrm{~cm}^{-1}$ is broad and appears to split in the ${ }^{36} \mathrm{~S}$-substituted FdVI spectrum. As with other [2Fe-2S] Fds, the strong $\mathrm{B}_{3 \mathrm{u}^{\mathrm{t}}}$ mode, now of $\mathrm{A}_{1}$ symmetry, exhibits a modest ${ }^{36} \mathrm{~S}$-shift to lower energy, from 276 to $267 \mathrm{~cm}^{-1}$. From the variation between 488 and 515 $\mathrm{nm}$ excitation, the next higher feature can tentatively be decomposed into 2 bands at 308 and $315 \mathrm{~cm}^{-1}$. This proposed splitting is confirmed as two resolved peaks at 301 and $309 \mathrm{~cm}^{-1}$ in the ${ }^{36} \mathrm{~S}$ Raman spectrum with $515 \mathrm{~nm}$ excitation. Two additional strong bands are seen at 381 and $402 \mathrm{~cm}^{-1}$, and their shifts are summarized in Table 2.

NRVS. The ${ }^{57} \mathrm{Fe}$ PVDOS for oxidized and reduced Rc FdVI and $A a$ Fd5 are also presented in Figures 1 and 2, and the individual peak positions are listed in Tables 1 and 2. In contrast with previous rubredoxin NRVS data (61), where individual modes were not well-resolved, there are a number of sharp features in the oxidized $R c$ FdVI spectra. These include peaks at $421 \mathrm{~cm}^{-1}$ and $393 \mathrm{~cm}^{-1}$ that presumably correspond, respectively, to $\mathrm{B}_{2 \mathrm{u}^{\mathrm{b}}}$ asymmetric $\mathrm{Fe}-\mathrm{S}^{\mathrm{b}}$ stretch and $\mathrm{A}_{\mathrm{g}}{ }^{\mathrm{b}} \mathrm{Fe}-\mathrm{S}^{\mathrm{b}}$ stretch modes. These bands exhibit large (16 or $11 \mathrm{~cm}^{-1}$, respectively) ${ }^{36} \mathrm{~S}$ isotope shifts (Figure 1) that are the same, within experimental error, as those seen in the Raman data. The fluctuations in the region above $420 \mathrm{~cm}^{-1}$, where we do not expect significant NRVS, are a useful gauge of the experimental noise.

The strongest PVDOS features occur in a broad band between $\sim 300$ and $360 \mathrm{~cm}^{-1}$. There are 2 peaks at 321 and $341 \mathrm{~cm}^{-1}$, but the overall width suggests a number of unresolved bands. In the ${ }^{36} \mathrm{~S}$ sample spectrum, peaks at $\sim 310$ and $290 \mathrm{~cm}^{-1}$ emerge from under this envelope, presumably because some near degenerate modes shift more than others. In contrast with the resonance Raman, where the strongest feature is often the $\mathrm{B}_{3 \mathrm{u}}{ }^{\mathrm{t}}$ band at $\sim 290 \mathrm{~cm}^{-1}$, there is very little NRVS intensity in this region. This is consistent with the $\mathrm{B}_{3 u^{t}}$ assignment because in this mode, attributed to an asymmetric combination of the two $\mathrm{FeS}_{4}$ breathing modes (62), there is very little $\mathrm{Fe}$ motion.

Significant PVDOS amplitude also occurs between $\sim 15$ and $240 \mathrm{~cm}^{-1}$ with a distinct local maximum at $\sim 190 \mathrm{~cm}^{-1}$ and an overall peak at $\sim 78 \mathrm{~cm}^{-1}$ (Figure 1). The $190 \mathrm{~cm}^{-1}$ band, also seen in the $R c$ FdVI Raman, and similar bands at $197-210 \mathrm{~cm}^{-1}$ in model compounds have been assigned as $\mathrm{A}_{\mathrm{g}}{ }^{\mathrm{Fe}-\mathrm{Fe}}$ stretching modes (24). The PVDOS features below $60 \mathrm{~cm}^{-1}$ in both ${ }^{36} \mathrm{~S} R c$ FdVI spectra are most likely artifacts of background subtraction since the resolution was lower $\left(\sim 12 \mathrm{~cm}^{-1}\right)$ during the measurements for these samples.

In the spectra for the reduced protein, the high frequency band at $421 \mathrm{~cm}^{-1}$ shifts down to $400 \mathrm{~cm}^{-1}$, and the 393 $\mathrm{cm}^{-1}$ feature moves to $382 \mathrm{~cm}^{-1}$. Both of the reduced peaks show further $\sim 15 \mathrm{~cm}^{-1}$ shifts upon ${ }^{36} \mathrm{~S}$ substitution. A group of broad features initially between $\sim 300$ and 360 $\mathrm{cm}^{-1}$ moves to between $\sim 270$ and $340 \mathrm{~cm}^{-1}$. An especially interesting peak is seen at $\sim 276 \mathrm{~cm}^{-1}$ in both the natural abundance and ${ }^{36} \mathrm{~S}$ PVDOS. Johnson and co-workers 


\section{Energy (meV)}

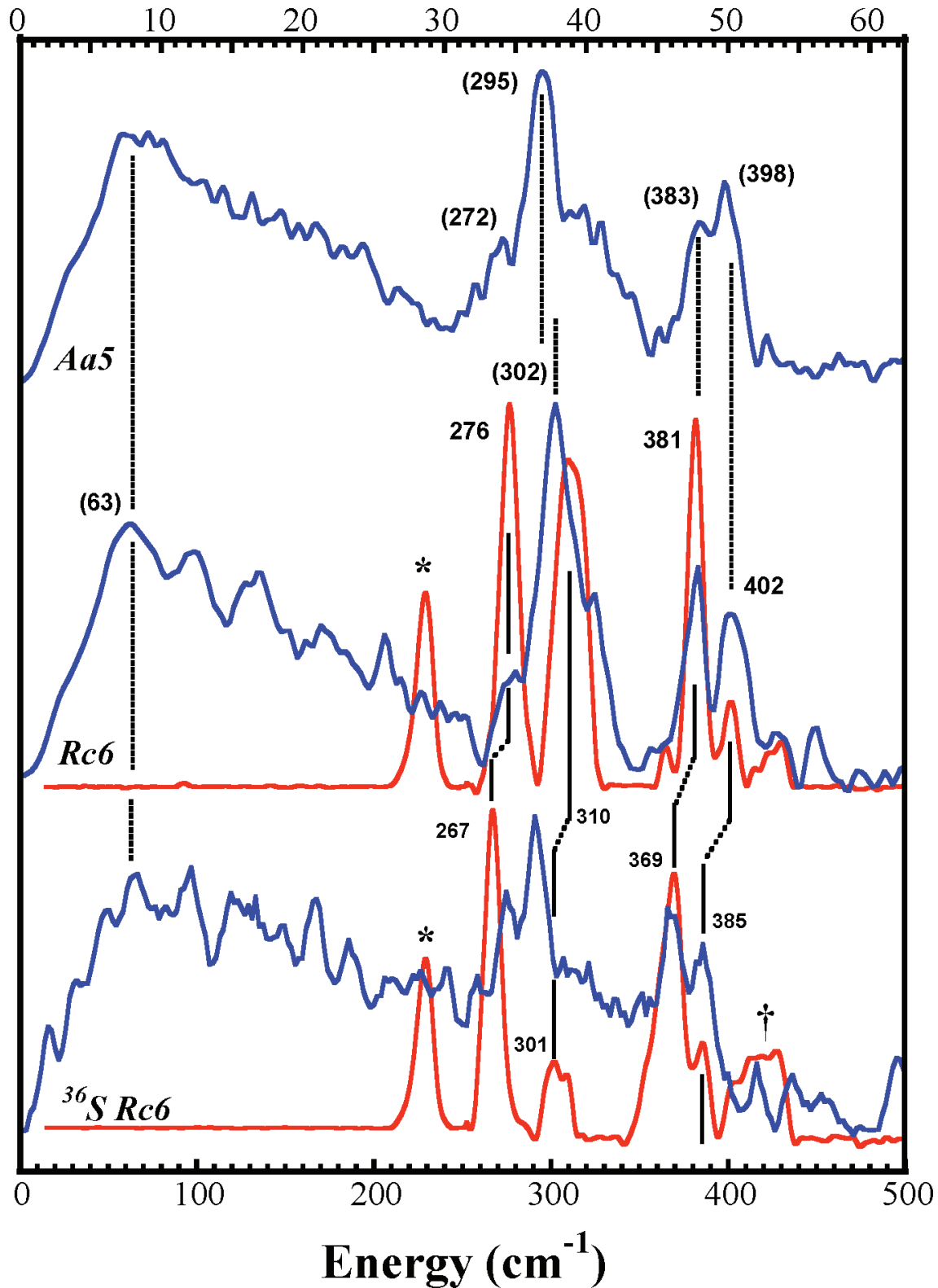

FIGURE 2: Top to bottom: resonance Raman spectra, using excitation at $515 \mathrm{~nm}$ (red line), compared with ${ }^{57} \mathrm{Fe}$ PVDOS (blue line) for reduced, ${ }^{57} \mathrm{Fe}$-enriched (a) $A a \mathrm{Fd5}$, (b) $R c$ FdVI, and (c) ${ }^{36} \mathrm{~S}^{\mathrm{b}}$-substituted $R c$ FdVI. * Marks ice band, and $\dagger$ marks possible dithionite decomposition product in Raman spectra. Dashed vertical lines highlight common PVDOS features between spectra; solid vertical lines mark Raman peak positions. Numbers in parentheses refer to PVDOS peaks; the remaining values are Raman peak positions.

Table 2: Mode Assignments and Calculated and Observed $\mathrm{Fe}-\mathrm{S}$ Stretching Frequencies, ${ }^{36} \mathrm{~S}$ Isotope Shifts for Reduced $R c$ FdVI Using the $\mathrm{C}_{2 \mathrm{~h}}$ $\mathrm{Fe}_{2} \mathrm{~S}_{2}(\mathrm{SCC})_{4}$ Model

\begin{tabular}{|c|c|c|c|c|c|c|c|c|c|c|c|}
\hline \multicolumn{3}{|c|}{ mode label } & \multicolumn{2}{|c|}{ Pdx, Ado Raman ${ }^{a}$} & \multicolumn{2}{|c|}{${ }^{57} \mathrm{Fe} R c$ FdVI Raman } & \multicolumn{2}{|c|}{${ }^{57} \mathrm{Fe} R c$ FdVI NRVS } & \multicolumn{3}{|c|}{ calculated values } \\
\hline $\mathrm{D}_{2 \mathrm{~h}}$ & $\mathrm{C}_{2 \mathrm{~h}}$ & $\mathrm{C}_{2 \mathrm{v}}$ & $v\left(\mathrm{~cm}^{-1}\right)$ & $\Delta v{ }^{34} \mathrm{~S}\left(\mathrm{~cm}^{-1}\right)$ & $v\left(\mathrm{~cm}^{-1}\right)$ & $\Delta v{ }^{36} \mathrm{~S}\left(\mathrm{~cm}^{-1}\right)$ & $v\left(\mathrm{~cm}^{-1}\right)$ & $\Delta v^{36} \mathrm{~S}\left(\mathrm{~cm}^{-1}\right)$ & $v\left(\mathrm{~cm}^{-1}\right)$ & $\Delta v^{36} \mathrm{~S}\left(\mathrm{~cm}^{-1}\right)$ & $e_{\mathrm{Fe}}^{2}$ \\
\hline $\mathrm{B}_{2 \mathrm{u}}^{\mathrm{b}}$ & $\mathrm{B}_{\mathrm{u}}^{\mathrm{b}}$ & $\mathrm{B}_{1}$ & 406398 & 4.54 .5 & 402 & 17 & 400 & 15 & 399.5 & 13.6 & 0.383 \\
\hline $\mathrm{Ag}_{\mathrm{g}}^{\mathrm{b}}$ & $A_{g}^{b}$ & $\mathrm{~A}_{1}$ & 381377 & 4.24 .5 & 381 & 13 & 382 & 15 & 380.9 & 14.7 & 0.278 \\
\hline $\mathrm{B}_{1 \mathrm{u}}{ }^{\mathrm{t}}$ & $\mathrm{A}_{\mathrm{u}}{ }^{\mathrm{t}}$ & $\mathrm{B}_{2}$ & 319 & 0.6 & & & 324 & & 326.2 & 0 & 0.373 \\
\hline $\mathrm{B}_{2 \mathrm{~g}} \mathrm{t}^{\mathrm{t}}$ & $\mathrm{Bg}^{\mathrm{t}}$ & $\mathrm{B}_{2}$ & & & & & 302 & & 303.1 & 0 & 0.354 \\
\hline$A_{g}{ }^{t}$ & $\mathrm{~A}_{\mathrm{g}}^{\mathrm{t}}$ & $A_{1}$ & 307307 & 3.0 & $308(\mathrm{u})$ & 7 & 306 (ss) & 7 & 291.2 & 2.4 & 0.335 \\
\hline
\end{tabular}

${ }^{a}$ Ref (21). s, shoulder; ss, small shoulder; u, unresolved.

predicted that the FeII-( $\left.\mathrm{S}^{\mathrm{t}}\right)$ stretch would occur in the region, but it lacked resonance Raman intensity (21).
Normal Mode Analysis. The resonance Raman spectra of $[2 \mathrm{Fe}-2 \mathrm{~S}]$ ferredoxins $(21-23)$ and $\left[\mathrm{Fe}_{2} \mathrm{~S}_{2}(\mathrm{SR})_{4}\right]^{\mathrm{n}-}$ model com- 


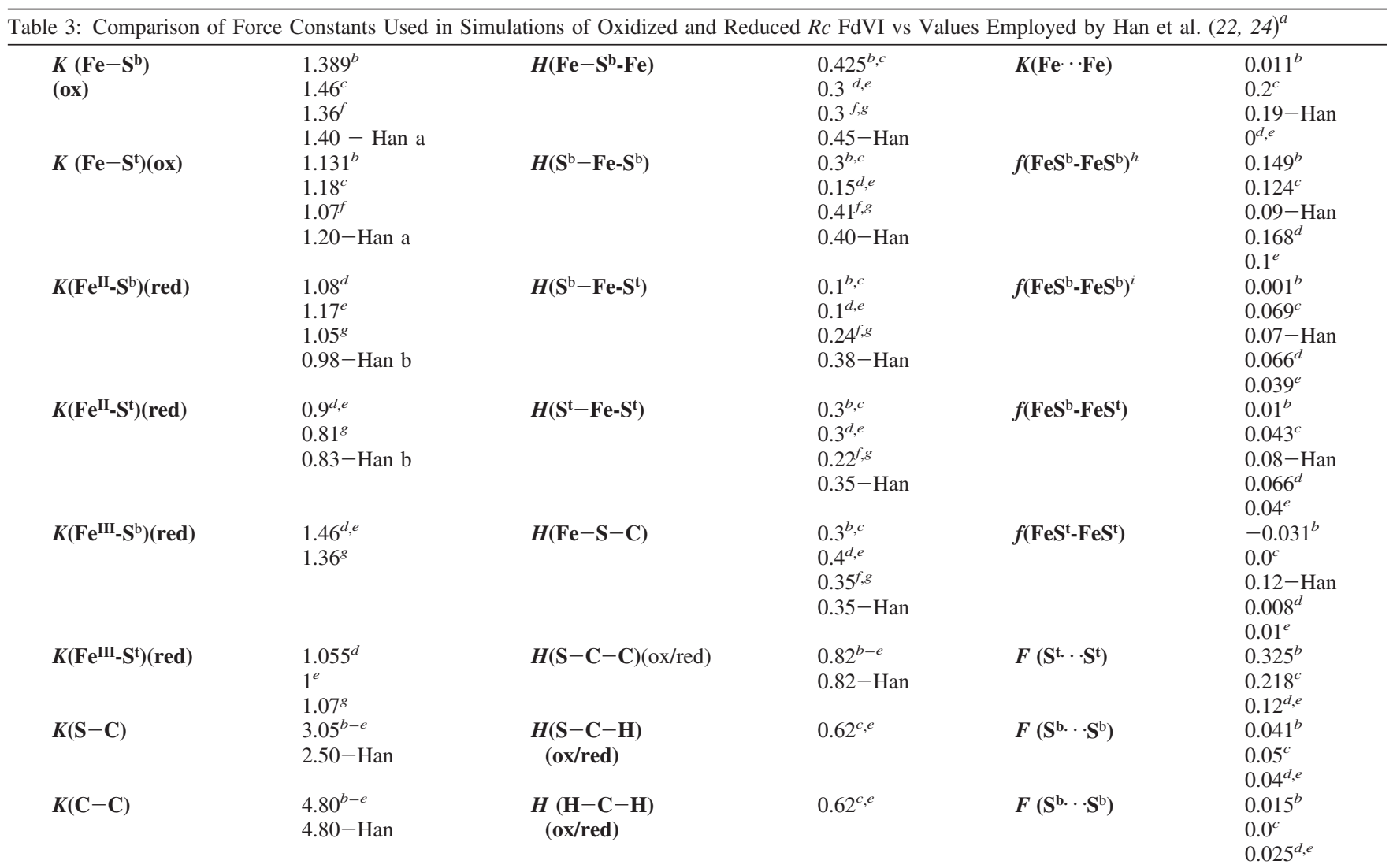

\footnotetext{
${ }^{a}$ See text for discussion of errors. ${ }^{b}$ This work, $\mathrm{C}_{2 \mathrm{~h}} \mathrm{Fe}_{2} \mathrm{~S}_{2}(\mathrm{SCC})_{4}$ for oxidized $R c$ FdVI. ${ }^{c}$ This work, $\mathrm{C}_{1} \mathrm{Fe}_{2} \mathrm{~S}_{2}(\mathrm{~S} \text {-cysXYZZ' })_{4}$ for oxidized $R c$ FdVI. ${ }^{d}$ This work, $\mathrm{C}_{2 \mathrm{~h}} \mathrm{Fe}_{2} \mathrm{~S}_{2}(\mathrm{SCC})_{4}$ for reduced $R c$ FdVI. ${ }^{e}$ This work, $\mathrm{C}_{1} \mathrm{Fe}_{2} \mathrm{~S}_{2}\left(\mathrm{~S}\right.$-cysXYZZ') ${ }_{4}$ for reduced $R c$ FdVI. ${ }^{f}$ This work, full protein model for oxidized $R c$ FdVI. ${ }^{g}$ This work, full protein model for reduced $R c$ FdVI. ${ }^{h}$ Common atom is $\mathrm{S}^{\mathrm{b}} .{ }^{i}$ Common atom is Fe; units for force constants: $K=$ stretching (mdyn/ $\AA), H=$ bending ( $\left.\operatorname{mdyn} \AA / \mathrm{rad}^{2}\right), F=$ nonbonded interaction (mdyn/ $\AA$ ), $f=$ stretch-stretch and stretch-bend interaction (mdyn/rad); Han: ref (24); Han-a: oxidized adrenodoxin parameter from ref (22); Han - b: reduced adrenodoxin parameter from ref (22).
}

plexes (24) have been interpreted with empirical force fields, and our analysis again relies on much of this body of work. As with previous rubredoxin NRVS studies (61), we began with small, high symmetry models, and we then progressively both increased the model size and lowered the symmetry. The calculated frequencies and ${ }^{36} \mathrm{~S}$ isotope shifts for the high frequency normal modes of these simple models are compared with the experimental data in Tables 1 and 2, while the resulting parameters are summarized in Table 3. Comparisons between experimental and calculated $D_{F e}(\bar{v})$ for oxidized $R c$ FdVI are shown in Figure 3.

$\mathrm{Fe}_{2} \mathrm{~S}_{2} \mathrm{~S}_{4}^{\prime}$ Models. The simplest model for the redox active site is a $\mathrm{Fe}_{2} \mathrm{~S}_{2} \mathrm{~S}_{4}^{\prime}$ model in $\mathrm{D}_{2 \mathrm{~h}}$ symmetry. This is a reasonable approximation for the geometry of the central $\mathrm{Fe}_{2} \mathrm{~S}_{6}$ cluster (Chart 2). We started with this model and adjusted the Urey-Bradley force field parameters to match the main peaks in the experimental $D_{\mathrm{Fe}}(\bar{v})$ spectrum. As discussed previously for $\left[\mathrm{Fe}_{2} \mathrm{Cl}_{6}\right]^{2-}(63)$ and $\left[\mathrm{Fe}_{2} \mathrm{~S}_{2} \mathrm{Cl}_{4}\right]^{2-}(60,64)$, this $\mathrm{D}_{2 \mathrm{~h}}$ model yields 8 modes that are primarily $\mathrm{Fe}-\mathrm{X}$ stretch in character, and 7 of these are NRVS-active.

The $\mathrm{Fe}-\mathrm{S}$ stretching modes occur between 280 and 420 $\mathrm{cm}^{-1}$. As deduced from empirical force fields (24) or DFT analysis (65), the highest frequency modes primarily involve more $\mathrm{Fe}-\mathrm{S}^{\mathrm{b}}$ motion, while the lowest frequency modes are mostly $\mathrm{Fe}-\mathrm{S}^{\mathrm{t}}$ in nature. We note that the $288 \mathrm{~cm}^{-1}\left(\mathrm{~B}_{3 \mathrm{u}^{\mathrm{t}}}\right)$ mode, which is often the strongest Raman feature, is essentially invisible in the NRVS data, indicating the lack of Fe kinetic energy in this mode. The lack of Fe motion in the $\mathrm{B}_{3 \mathrm{u}}{ }^{\mathrm{t}}$ mode was previously confirmed by the absence of isotope shifts in model compounds substituted with ${ }^{54} \mathrm{Fe}(24)$. The eigenvector for this mode has been described as "concerted out-of-phase breathing motion of the linked $\mathrm{FeS}_{4}$ tetrahedra" (22). Although differential H-bonding can lead to large resonance Raman intensity for this mode, most of the motion in this mode involves the sulfur atoms, and it is consequently weak in the NRVS. A similar absence of NRVS intensity (vs strong resonance Raman intensity) was observed for the $\mathrm{FeS}_{4}$ breathing modes in oxidized and reduced rubredoxin (61).

$\mathrm{Fe}_{2} \mathrm{~S}_{2}(\mathrm{SCC})_{4}$ Models. The orientation of the cysteine carbons, which is reflected in the $\mathrm{Fe}-\mathrm{S}-\mathrm{C}_{\beta}-\mathrm{C}_{\alpha}$ dihedral angle, has frequently been cited as a major determinant of the $\mathrm{Fe}-\mathrm{S}$ stretching frequencies (66). Since the importance of coupling with cysteine side chain motion is well-documented, we proceeded with $\mathrm{Fe}_{2} \mathrm{~S}_{2}(\mathrm{SCC})_{4}$ models in $\mathrm{C}_{2 \mathrm{~h}}$ symmetry. The masses of the $\mathrm{C}_{\beta}$ and $\mathrm{C}_{\alpha}$ carbons were increased to model the presence of 2 or 3 hydrogens, respectively. We again adjusted the Urey-Bradley force field parameters to maximize correspondence with the experimental $D_{F e}(\bar{v})$ spectrum for both natural abundance $\mathrm{S}$ and ${ }^{36} \mathrm{~S}$-bridge-substituted oxidized $R c$ FdVI, while at the same time reproducing as well as possible the observed Raman frequencies. As shown in Table 1, the calculated normal-mode frequencies for these $\mathrm{Fe}_{2} \mathrm{~S}_{2}(\mathrm{SCC})_{4}$ models agree well with both the NRVS and Raman data, especially for the 393 and $421 \mathrm{~cm}^{-1}\left(\mathrm{~B}_{2 \mathrm{u}}{ }^{\mathrm{b}}\right.$ and $\left.\mathrm{A}_{\mathrm{g}} \mathrm{b}\right)$ modes that are predominantly $\mathrm{Fe}-\mathrm{S}^{\mathrm{b}}$ character. Below $\sim 200 \mathrm{~cm}^{-1}$ are modes that are primarily $\mathrm{S}-\mathrm{Fe}-\mathrm{S}$ bend and $\mathrm{Fe}-\mathrm{S}-\mathrm{Fe}$ bend in nature, along with torsional modes and vibrations involving 


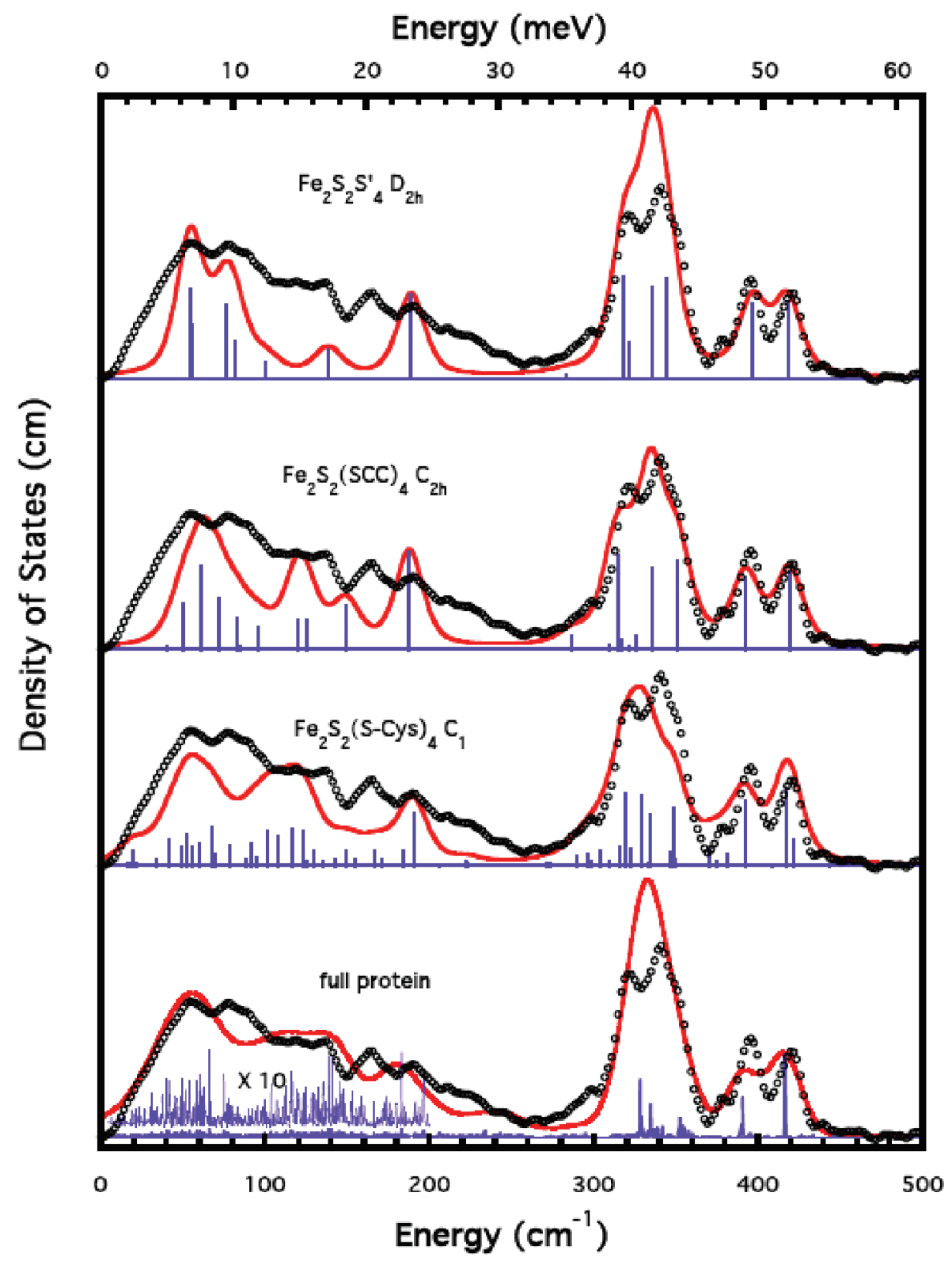

FIGURE 3: Simulations for oxidized $R c$ FdVI. Sticks represent intensities of individual normal modes. Top to bottom: ${ }^{57} \mathrm{Fe}$ PVDOS ( $\circ \circ$ ) and simulation (red line) for (a) $\mathrm{Fe}_{2} \mathrm{~S}_{2} \mathrm{~S}_{4}^{\prime}$ model in $\mathrm{D}_{2 \mathrm{~h}}$ symmetry; (b) $\mathrm{C}_{2 \mathrm{~h}} \mathrm{Fe}_{2} \mathrm{~S}_{2}$ (SCC) s $_{4}$ model; (c) chromophore-in-protein model using crystal structure coordinates; (d) full protein analysis. In (a-c), PVDOS has been broadened with a $10 \mathrm{~cm}^{-1}$ Voigt profile $(50 \%$ Gaussian, $50 \%$ Lorentzian, $10 \mathrm{~cm}^{-1}$ fwhm) to account for experimental and natural linewidths. In (d), an $8 \mathrm{~cm}^{-1}$ Gaussian broadening was used.

large-scale protein motion. In the $\left[\mathrm{Fe}_{2} \mathrm{~S}_{2} \mathrm{Cl}_{4}\right]^{2-} \mathrm{NRVS}$, several of these modes are clearly resolved, at 101,145 , and $177 \mathrm{~cm}^{-1}$ (64). However, in the Aa Fd5 and Rc FdVI PVDOS, there is instead a broad pyramid of intensity between 20 and $220 \mathrm{~cm}^{-1}$. The $\mathrm{C}_{2 \mathrm{~h}}$ symmetry small model simulation captures some of the local intensity maxima, but as expected, the calculation predicts narrower features than are actually observed.

A referee has inquired as to the significance of the parameters reported in Table 3. Since the stretching force constants are most important for the high frequency portion of the spectrum, we investigated how large a change in one parameter (with all other parameters fixed) was required to double the residual defined in eq 4, restricted to the region above $250 \mathrm{~cm}^{-1}$. The stretching force constants for $\mathrm{Fe}$ and bridging sulfides, $K_{\mathrm{Fe}-\mathrm{S}(\mathrm{b})}$, and for $\mathrm{Fe}$ and terminal thiolate, $K_{\mathrm{Fe}-\mathrm{S}(\mathrm{t})}$, were the most constrained, to better than $0.5 \%$, with the residuals doubling over intervals of \pm 0.007 mdyne $\AA^{-1}$ and \pm 0.008 mdyne $\AA^{-1}$, respectively. The error estimates for the bending force constants used the entire NRVS data range because these parameters affect the lower frequency region. With these procedures, the bending force constants could be changed by $\pm 10 \%$ before doubling the residual. All of these error estimates become several-fold larger if correlated parameters are allowed to float. We therefore note the point made some time ago by Spiro and co-workers: "Although agreement with observation cannot be taken as proof that the force field is correct, the accurate calculation of isotope shifts does imply that the calculated eigenvectors are good approximations to the normal modes (67)." In the current set of experiments, the ${ }^{36} \mathrm{~S}$ shifts help define the amount of bridging $\mathrm{S}$ motion in a given normal mode, while the NRVS intensity constrains the amount of ${ }^{57} \mathrm{Fe}$ motion in the same.

Chromophore in Protein Models. In order to better capture the coupling between [2Fe-2S] cluster modes and the protein side chain motion, we further expanded our model to include all of the ligand cysteine atoms, as well as the carbonyl $\mathrm{C}$ and $\mathrm{O}$ of the residue adjacent to the cysteine $\mathrm{N}$, and the amide 
$\mathrm{N}$ of the residue bound to the cysteine carbonyl. The symmetry was relaxed to $C_{1}$, and all atoms were placed at the crystal structure coordinates. Initial values for the force constants associated with these peripheral atoms were obtained from the CHARMM molecular modeling software (68).This approach was employed by Qiu and co-workers in their chromophore in protein calculations (69), who included all of the protein atoms in their model for plastocyanin, but assigned masses of 999 to polypeptide atoms more than 6 atoms away (via the ligating side chain) from the central $\mathrm{Cu}$. The force constants for the core atoms were again optimized, with respect to both oxidized and reduced PVDOS (Table 3 ). The resultant $K_{\mathrm{Fe}-\mathrm{S}(\mathrm{t})}$ for the oxidized protein was 1.18 mdyne $\AA^{-1}$, comparable to the 1.20 mdyne $\AA^{-1}$ used by Han and co-workers, or for rubredoxin work, the 1.27 mdyne $\AA^{-1}$ used by Czernuszewicz et al. (27) and the 1.36 mdyne $\AA^{-1}$ value used by Saito and co-workers (70). For $K_{\mathrm{Fe}-\mathrm{S}(\mathrm{b})}$, our value 1.46 mdyne $\AA^{-1}$ is slighter larger than the 1.40 mdyne $\AA^{-1}$ used by Han and co-workers, and this may be due to the higher $\mathrm{B}_{2 \mathrm{u}}{ }^{\mathrm{b}}$ mode frequency observed for oxidized $R c$ FdVI. The bending force constants, $H_{\mathrm{S}(\mathrm{b}) \mathrm{FeS}(\mathrm{b})}$ and $H_{\mathrm{S}(\mathrm{t}) \mathrm{FeS}(\mathrm{t})}$ were 0.3 mdyne- $\AA$, compared to the 0.35 or 0.43 mdyne- $\AA$ values, respectively, used by Czernuszewicz (27) or Saito (70). Both of these groups were much less concerned with the bending mode region of the spectrum. As seen in Figure 3, the widths and intensities of the spectral features in the $\mathrm{Fe}-\mathrm{S}$ stretching region above $300 \mathrm{~cm}^{-1}$ are reasonably well captured by this model. However, the simulation below $260 \mathrm{~cm}^{-1}$ remains too structured and is missing intensity. This suggests that, as argued previously (22), the $\mathrm{Fe}-\mathrm{S}$ stretching modes are indeed localized to the cluster and cysteine ligands, while the bending and torsional modes of the clusters are more coupled to the protein and delocalized, and a larger model is needed to simulate this region.

Full Protein Calculations. Low frequency modes $(<100$ $\mathrm{cm}^{-1}$ ) have not been observed before in [2Fe-2S] ferredoxins. In blue $\mathrm{Cu}$ proteins $(71,72)$ and heme proteins $(73-75)$, modes between 20 and $80 \mathrm{~cm}^{-1}$ have been referred to as phonon-like (76) or as delocalized mode(s) involving the protein skeleton motion (77). In $\mathrm{Fe}_{2} \mathrm{X}_{6}$ clusters, a number of low frequency cluster modes, such as $\mathrm{MX}_{2}$ wag, twist, rock, and ring puckering, have also been predicted for the region below $100 \mathrm{~cm}^{-1}$ (63), but for technical reasons, they have never been observed in bioinorganic $\mathrm{Fe}-\mathrm{S}$ clusters. In $\mathrm{Fe}-\mathrm{S}$ proteins, these low frequency cluster modes could be expected to couple to the many protein modes of comparable frequency. At the lowest end of the spectrum, collective motion of large segments of polypeptide might carry the cluster as a whole body, similar to the acoustic modes seen for lower molecular weight complexes.

To better model and characterize the low frequency region of the spectrum, the normal modes were calculated for a model with all of the protein atoms, along with 56 water molecules, as shown in Figure 5. These calculations used CHARMM22 parameters for the protein and initially used the $\mathrm{Fe}-\mathrm{S}$ parameters from the $\mathrm{D}_{2 \mathrm{~h}} \mathrm{Fe}_{2} \mathrm{~S}_{2}(\mathrm{SCC})_{4}$ model for the cluster. The $\mathrm{Fe}-\mathrm{S}$ force constants were then adjusted manually to optimize the agreement between calculated and observed PVDOS. Of course, before the CHARMM normal mode calculation, the protein coordinates from the X-ray crystal structure were refined to minimize the energy in the
CHARMM22 force field, and thus, the small model Vibratz calculations and the total protein CHARMM calculations actually use slightly different structures for the $[2 \mathrm{Fe}-2 \mathrm{~S}]$ cluster site. This is one fundamental reason why the force constants are not perfectly transferable between the two calculations. Furthermore, the best $\mathrm{Fe}-\mathrm{S}$ parameters for Vibratz and CHARMM are necessarily different because the force fields are quite different. The CHARMM22 force field has Coulombic and van der Waals terms (some of which indirectly incorporate hydrogen bonding) that are absent from the Vibratz Urey-Bradley force field.

The results demonstrate that the protein influence on the NRVS can be modeled without adjusting any polypeptide parameters. Since we have left the polypeptide part of the CHARMM22 force field unchanged, our final PVDOS prediction for this region is a natural consequence of the coupling of $[2 \mathrm{Fe}-2 \mathrm{~S}]$ cluster modes with low frequency protein modes.

We have used the eigenvectors from the full protein CHARMM calculation to illustrate the differences between different regions of the PVDOS spectrum (Figure 5). We chose a few specific modes for a variety of reasons. The 13 and $14 \mathrm{~cm}^{-1}$ modes were chosen because they are highly collective protein modes that also contain a large amount of coherent $[2 \mathrm{Fe}-2 \mathrm{~S}]$ cluster motion. The $288 \mathrm{~cm}^{-1}$ mode was chosen because it is the strongest band in the resonance Raman spectrum. Finally, the $416 \mathrm{~cm}^{-1}$ mode was chosen because it is the highest frequency mode with significant NRVS intensity. Animations of these motions are available as Supporting Information.

The lowest frequency eigenvectors, exemplified by the modes at $\sim 13-14 \mathrm{~cm}^{-1}$, involve delocalized protein skeleton motion and in-phase motion of the entire $\mathrm{Fe}_{2} \mathrm{~S}_{2}{ }_{2} \mathrm{~S}_{4}$ unit as a nearly rigid body (Figure 5). For the $13 \mathrm{~cm}^{-1}$ mode, concerted motion of the $\mathrm{Fe}-\mathrm{S}$ cluster along with the nearby polypeptide is coupled to motion of the $\mathrm{C}$-terminus and nearby residues such that the two parts of the proteins move in opposite directions in a large-scale stretching motion (Figure 5a). For the $14 \mathrm{~cm}^{-1}$ mode, concerted motion of the [2Fe-2S] cluster along with nearby residues is countered by motion of polypeptide near the $\mathrm{N}$ terminus (Figure $5 \mathrm{~b}$ ). Higher frequency modes, such as those at 288 and $416 \mathrm{~cm}^{-1}$, exhibit much more localized motion of the $[2 \mathrm{Fe}-2 \mathrm{~S}]$ cluster. Of special interest is the mode at $288 \mathrm{~cm}^{-1}$ (Figure $5 \mathrm{c}$ ), previously assigned as an out-of-phase breathing motion of the two connected $\mathrm{FeS}_{4}$ tetrahedra (24). This mode has virtually no Fe motion so that it is nearly invisible by NRVS, despite being the strongest feature in the resonance Raman spectra. In contrast, the mode at $416 \mathrm{~cm}^{-1}$ (Figure 5d) is relatively weak in the Raman but has significant NRVS intensity due to $\mathrm{Fe}$ movement in the $\mathrm{Fe}-\mathrm{S}^{\mathrm{b}}$ stretching motion.

Reduced Rc FdVI. The analysis for reduced Rc FdVI followed lines similar to those used for the oxidized sample. For the $\mathrm{Fe}_{2} \mathrm{~S}_{2}(\mathrm{SCC})_{4}$ models, the atomic coordinates used $\mathrm{C}_{2 \mathrm{~h}}$ symmetry, but to allow for inequivalent $\mathrm{Fe}$ (II) and $\mathrm{Fe}$ (III) sites, we used $C_{1}$ symmetry for the normal mode calculations. The resulting comparisons between experimental and calculated $D_{F e}(\bar{v})$ for reduced $R c$ FdVI are shown in Figure 4. For the $\mathrm{Fe}(\mathrm{III})$ site, the optimized $\mathrm{Fe}-\mathrm{S}^{\mathrm{t}}$ stretch force constant was found to be $\sim 1$ mdyne $\AA^{-1}$, slightly lower than the 1.18 mdyne $\AA^{-1}$ value used in the oxidized cluster simulation. The $\mathrm{Fe}(\mathrm{III})-\mathrm{S}^{\mathrm{b}}$ stretch force constant derived for 


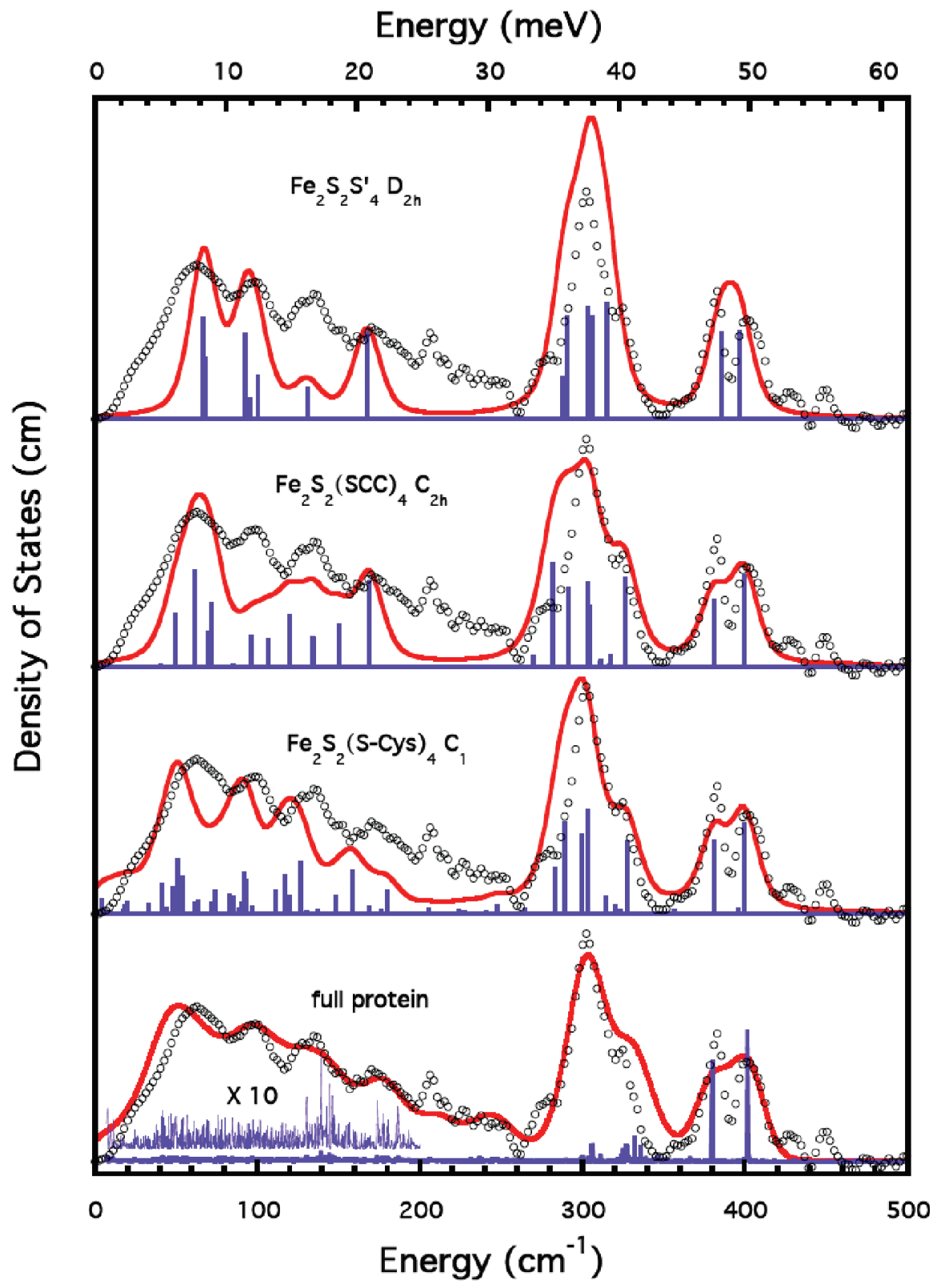

FIGURE 4: Simulations for reduced $R c$ FdVI. Top to bottom: ${ }^{57} \mathrm{Fe}$ PVDOS (。。 ) and simulation (red line) for (a) $\mathrm{Fe}_{2} \mathrm{~S}_{2} \mathrm{~S}_{4}{ }_{4}$ model in $\mathrm{D}_{2 \mathrm{~h}}$ symmetry; (b) $\mathrm{C}_{2 \mathrm{~h}} \mathrm{Fe}_{2} \mathrm{~S}_{2}(\mathrm{SCC})_{4}$ model; (c) chromophore-in-protein model using crystal structure coordinates; (d) full protein normal-mode analysis. In $(\mathrm{a}-\mathrm{c})$, calculated PVDOS has been broadened with a $10 \mathrm{~cm}^{-1}$ Voigt profile (50\% Gaussian, $50 \%$ Lorentzian, and $\left.10 \mathrm{~cm}{ }^{-1} \mathrm{fwhm}\right)$ to account for experimental and natural linewidths. In (d), an $8 \mathrm{~cm}^{-1}$ Gaussian broadening was used.

the partially reduced cluster was unchanged (both at 1.46 mdyne $\left.\AA^{-1}\right)$. For the Fe(II) site, significantly smaller $\mathrm{Fe}-\mathrm{S}^{\mathrm{t}}$ and $\mathrm{Fe}-\mathrm{S}^{\mathrm{b}}$ stretch force constants were found: 0.9 mdyne $\AA^{-1}$ and 1.17 mdyne $\AA^{-1}$, respectively. A $31 \%$ diminution, from 1.24 down to 0.92 mdyne/ $\AA$, was previously observed between oxidized and reduced rubredoxin (61). Our results are also in accord with the $30 \%$ reduction of $K_{\mathrm{Fe}-\mathrm{S}}$ inferred for the $\mathrm{Fe}(\mathrm{II})$ site in 2-Fe ferredoxins from the resonance Raman of the reduced forms (22). In contrast, we found that the bend force constants $H_{\mathrm{S}-\mathrm{Fe}-\mathrm{S}}$ are about the same for both oxidized and reduced $R c$ FdVI.

Localization of Normal Modes. As illustrated in Figures 3 and 4, progressively larger models for the environment of $\mathrm{Fe}$ in oxidized or reduced $R c$ FdVI produce better simulations of the ${ }^{57} \mathrm{Fe}$ PVDOS, especially in the low frequency regions. The normal mode calculations for even the simplest model, the $\mathrm{D}_{2 \mathrm{~h}}$ $\mathrm{Fe}_{2} \mathrm{~S}_{2} \mathrm{~S}_{4}{ }_{4}$ construct, adequately capture both the intensity and the frequency of the two highest energy features. These modes, assigned as $B_{2 u}$ and $A_{g}$ in $D_{2 h}$ symmetry, are found to be highly localized on the cluster, even when the model is expanded to the full protein structure (Figure 5).

Only the full protein calculations accurately capture the breadth of the spectra below $260 \mathrm{~cm}^{-1}$. Since the NRVS intensity is proportional to the fraction of kinetic energy from ${ }^{57} \mathrm{Fe}$ in a given normal mode, this reflects the fact that $\mathrm{Fe}$ motion is divided between a large number of modes that involve progressively larger numbers of atoms. The degree of localization of $\mathrm{Fe}-\mathrm{S}$ modes in rubredoxins and ferredoxins has been the subject of discussion for some time $(22,26,27,70,78)$. To better illustrate this issue on a quantitative basis, we evaluated the degree of collectivity $\kappa$ for the normal modes of $R c$ FdVI, and the results are presented in Figure 6.

The overall collectivity trend that we see for $R c$ FdVI (Figure 6) is quite similar to that observed in the original calculations for the small (46 amino acid) protein crambin (56). The collectivity values occur in a broad band, rising 

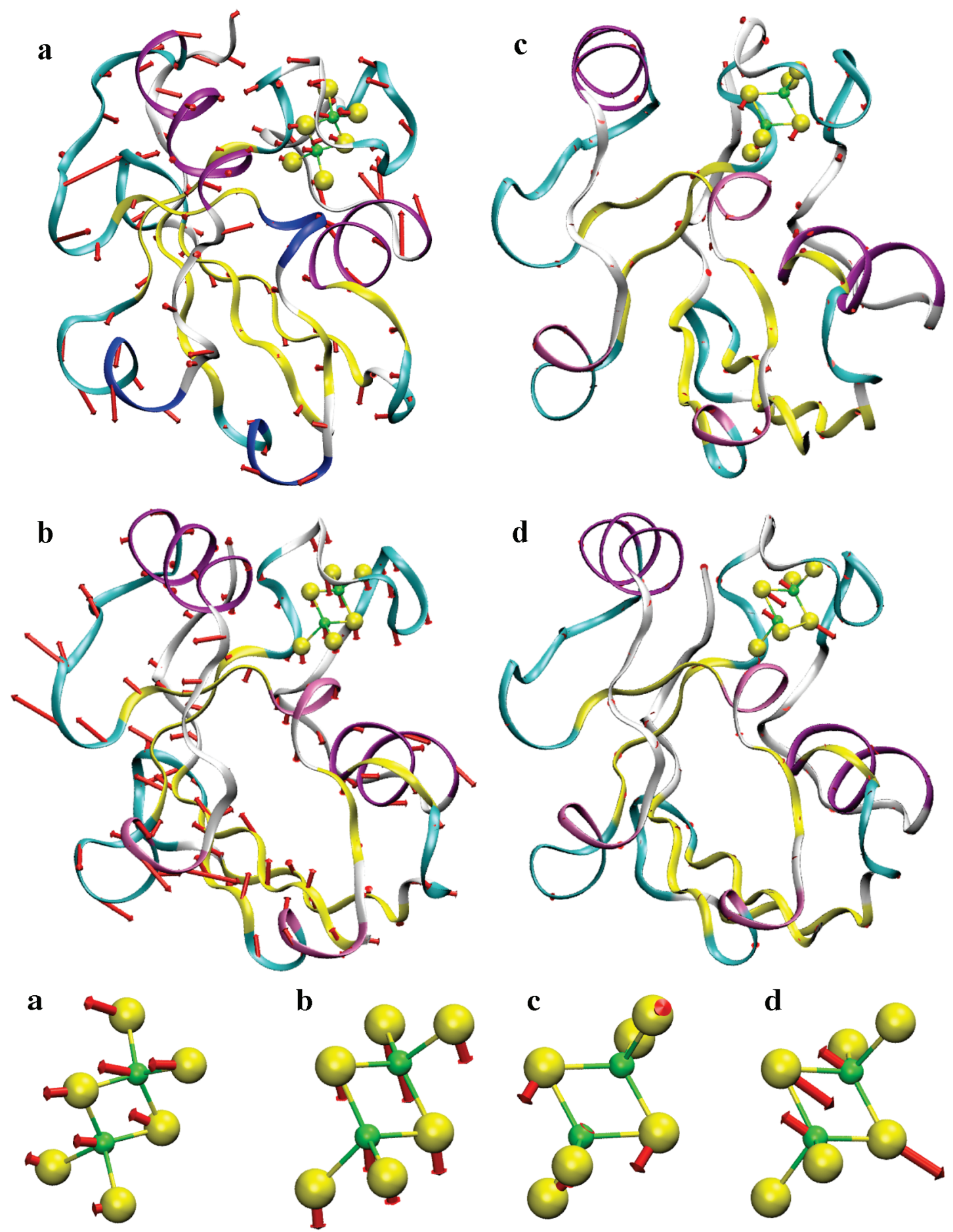

FIGURE 5: Illustration of molecular motion in normal modes derived from full protein analysis. Arrows represent relative magnitude and directions of $\mathrm{C} \alpha$ or cluster atom motion in oxidized $R c$ FdVI. Modes illustrated are (a) $13 \mathrm{~cm}^{-1}$, (b) $14 \mathrm{~cm}^{-1}$, (c) $288 \mathrm{~cm}^{-1}$, and (d) $416 \mathrm{~cm}^{-1}$. Figures were made with VMD (10).

from a range of $\sim 0.2-0.4$ (with some outliers) at 200 $\mathrm{cm}^{-1}$ to $\sim 0.4-0.6$ for the lowest frequencies. As noted by Tama and Sanejouand, $\kappa$ is analogous to the $\mathrm{W}$ term in Boltzmann's $S=k \log W$, and it is a measure of the degree of participation of all the atoms in a particular conformational change or normal mode. Thus, if all of the atoms have equal amounts of motion, $\kappa=1$, and in the limit that only a single atom moves, $\kappa=1 / N$, where in our case $N$ is the number of non-hydrogen protein atoms (797) plus 4 (for the atoms in the cluster). If the number of atoms involved in the normal mode is taken as $\kappa \mathrm{N}$, then these calculations show that the lowest frequency modes around $10-20 \mathrm{~cm}^{-1}$ are extensively delocalized over almost half or more of the polypeptide atoms.

At the other extreme, we found that the highest frequency cluster mode, calculated at a frequency of $416 \mathrm{~cm}^{-1}$ and illustrated in Figure 5, is quite localized. This mode, assigned as the $\mathrm{B}_{2 \mathrm{u}} \mathrm{Fe}-\mathrm{S}$ stretch in the $\mathrm{D}_{2 \mathrm{~h}}$ symmetry model, had a value of $\kappa=0.0092$, suggesting the involvement of $\sim 7.5$ atoms. This corresponds nicely to the view of this mode as localized on the $\mathrm{Fe}_{2} \mathrm{~S}_{2} \mathrm{~S}_{4}{ }_{4}$ core, and is in agreement with the strong NRVS and the large ${ }^{36} \mathrm{~S}$ isotope shift. The calculations suggest, however, that mode delocalization increases quite rapidly for lower frequencies. For a pair of modes at 390 

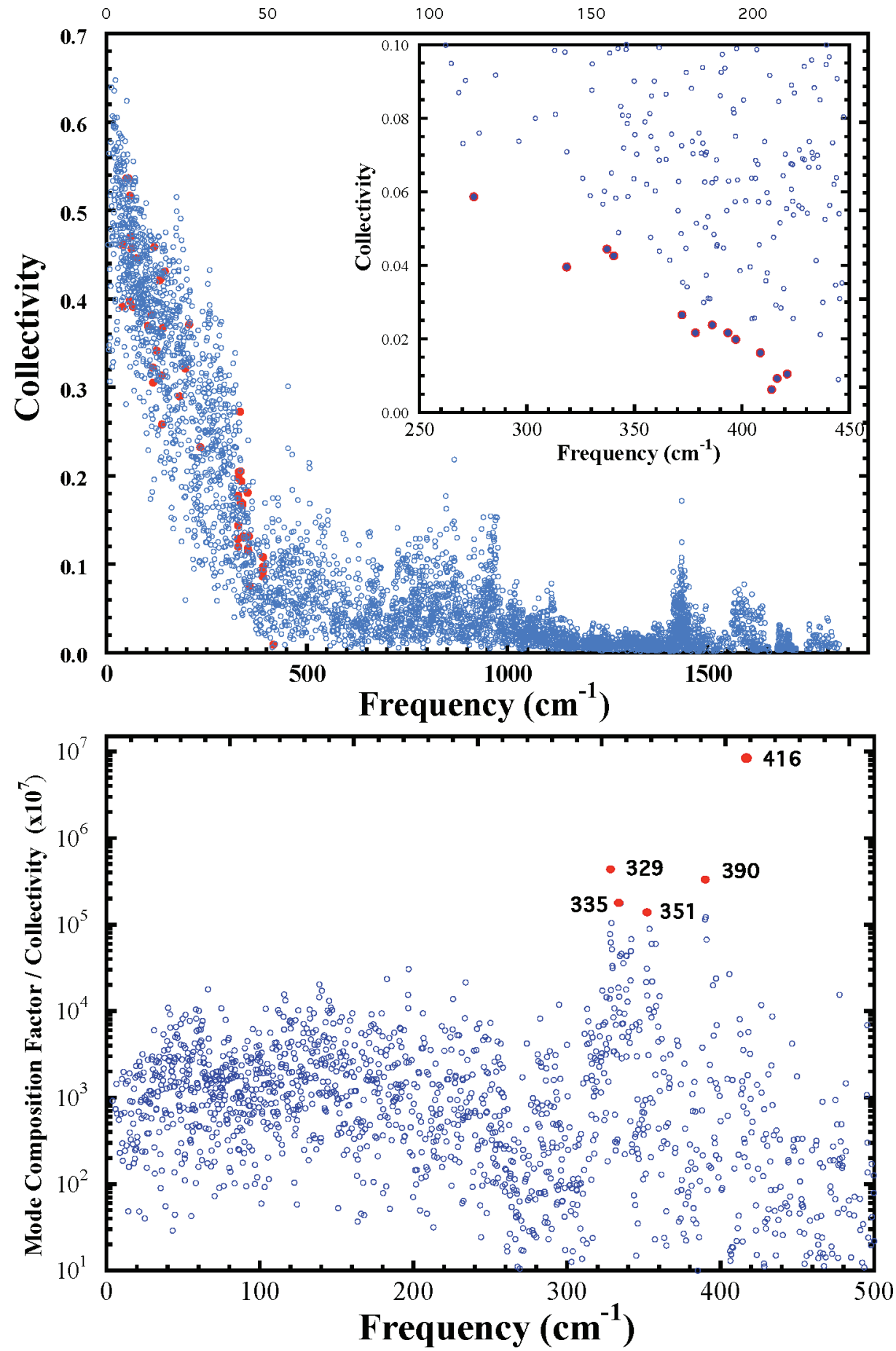

FIGURE 6: Top: degree of collectivity $(\kappa)$ for normal modes of oxidized Rc FdVI. Modes with largest mode composition factors are highlighted (red circles). In the inset, the highlighted modes (filled circles) are simply those with the lowest $\kappa$. Bottom: the mode composition factor divided by $\kappa$, to emphasize cluster-centered normal modes.

$\mathrm{cm}^{-1}$, corresponding to the $\mathrm{A}_{\mathrm{g}}$ motion in $\mathrm{D}_{2 \mathrm{~h}}$ symmetry. $\kappa$ $=0.086$ or 0.092 , corresponding to $70-74$ atoms, while a strong NRVS mode at $352 \mathrm{~cm}^{-1}$, corresponding approximately to $\mathrm{B}_{3 \mathrm{u}}{ }^{\mathrm{b}}$ motion, has $\kappa=0.11$. These values imply the involvement of all 4 cysteine residues as well as some neighboring atoms. Extensive delocalization of modes involving cysteine thiolates was inferred from the observation of ${ }^{15} \mathrm{~N}$ isotope shifts in the resonance Raman spectra of Anabaena ferredoxin (32). The CHARMM calculations suggest that even some nominally $\mathrm{Fe}-\mathrm{S}^{\mathrm{b}}$ modes can be quite delocalized. Finally, the bend modes in the $100-200 \mathrm{~cm}^{-1}$ range have $\kappa>0.25$, showing that these motions are extensively coupled with the motion of more than two dozen amino acids. We are currently exploring the relationship between the more collective normal modes and the conformational changes between oxidized and reduced $2 \mathrm{Fe}-2 \mathrm{~S}$ ferredoxins.

\section{SUMMARY}

The combined application of ${ }^{57} \mathrm{Fe}$ NRVS and resonance Raman spectroscopy, along with ${ }^{36} \mathrm{~S}$ labeling and full protein normal-mode analysis, has provided a broader view of $2 \mathrm{Fe}-$ $2 \mathrm{~S}$ cluster dynamics in ferredoxin electron transfer proteins. 
For oxidized $R c$ FdVI and $A a$ Fd5, additional modes are seen that are difficult to observe by Raman, including strong features below $100 \mathrm{~cm}^{-1}$. Furthermore, in the reduced protein, the $\mathrm{Fe}(\mathrm{II})$ site is equally accessible to the NRVS method, whereas the Raman is primarily sensitive to Fe(III) dynamics.

A special feature of NRVS is the potential for accurate intensity calculations; the amplitude of NRVS features reveals the fraction of kinetic energy due to Fe motion in a particular normal mode. Combined with its ability to observe low frequency modes, the NRVS data has allowed us to construct an empirical force field that also includes Fe-based bending and torsional motions. The coupling of cluster modes with protein motion has been successfully modeled by adding our empirical $\mathrm{Fe}-\mathrm{S}$ force constants to the CHARMM force field (without modification of the polypeptide parameters). Future studies will explore the relationship between low frequency normal modes and redox-induced conformational changes in ferredoxins.

\section{ACKNOWLEDGMENT}

We thank Yves Jouanneau for supplying the plasmid (pJA66) for expression of $R c$ FdVI.

\section{SUPPORTING INFORMATION AVAILABLE}

Raman data and torsion angle for some [2Fe-2S] ferredoxins are summarized in Table S1. Figure S1 shows experimental data for the average separation of $\mathrm{B}_{3 \mathrm{u}}{ }^{\mathrm{t}}$ mode and $\mathrm{A}_{\mathrm{g}}{ }^{\mathrm{t}}, \mathrm{B}_{2 \mathrm{~g}}{ }^{\mathrm{t}}$, and $\mathrm{B}_{3 \mathrm{u}}{ }^{\mathrm{b}}$ modes vs the average $\mathrm{Fe}-\mathrm{S}-\mathrm{C}-\mathrm{C}$ dihedral angle. Figures S2 and S3 show simulations of ${ }^{36} \mathrm{~S}$ data. Movies S1-S4 are animations of protein motions listed in Figure 5. This material is available free of charge via the Internet at http://pubs.acs.org.

\section{REFERENCES}

1. Meyer, J. (2008) Iron-sulfur protein folds, iron-sulfur chemistry, and evolution. J. Biol. Inorg. Chem 13, 157-170.

2. Bertini, I., Luchinat, C., Provenzani, A., Rosato, A., and Vasos, P. R. (2002) Browsing gene banks for $\mathrm{Fe}_{2} \mathrm{~S}_{2}$ ferredoxins and structural modeling of 88 plant-type sequences: an analysis of fold and function. Proteins 46, 110-127.

3. Fukuyama, K. (2004) Structure and function of plant-type ferredoxins. Photosynth. Res. 81, 289-301.

4. Hajirezaei, M.-R., Peisker, M., Tschiersch, H., Palatnik, J. F., Valle, E. M., Carrillo, N., and Sonnewald, U. (2002) Small changes in the activity of chloroplastic $\mathrm{NADP}^{+}$-dependent ferredoxin oxidoreductase lead to impaired plant growth and restrict photosynthetic activity of transgenic tobacco plants. Plant J. 29, 281-293.

5. Lange, H., Kaut, A., Kispal, G., and Lill, R. (2000) A mitochondrial ferredoxin is essential for biogenesis of cellular iron-sulfur proteins. Proc. Natl. Acad. Sci. U.S.A. 97, 1050-1055.

6. Mitou, G., Higgins, C., Wittung-Stafshede, P., Conover, R. C., Smith, A. D., Johnson, M. K., Gaillard, J., Stubna, A., Münck, E., and Meyer, J. (2003) An Isc-type extremely thermostable [2Fe2S] ferredoxin from Aquifex aeolicus. Biochemical, spectroscopic, and unfolding studies. Biochemistry 42, 1354-1364.

7. Armengaud, J., Meyer, C., and Jouanneau, Y. (1997) A [2Fe-2S] Ferredoxin (FdVI) Is Essential for growth of the photosynthetic bacterium Rhodobacter capsulatus. J. Bacteriol. 179, 3304-3309.

8. Sainz, G., Jakoncic, J., Sieker, L. C., Stojanoff, V., Sanishvili, N., Asso, M., Bertrand, P., Armengaud, J., and Jouanneau, Y. (2006) Structure of a [2Fe-2S] Ferredoxin from Rhodobacter capsulatus likely involved in Fe-S cluster biogenesis and conformational changes upon reduction. J. Biol. Inorg. Chem. 11, 235-246.

9. Kakuta, Y., Horio, T., Takahashi, Y., and Fukuyama, K. (2001) Crystal structure of Escherichia coli Fdx, an adrenodoxin-type ferredoxin involved in the assembly of iron-sulfur clusters. Biochemistry 40, 11007-11012.
10. Humphrey, W., Dalke, A., and Schulten, K. (1996) VMD-visual molecular dynamics. J. Mol. Graphics 14, 33-38.

11. DeLano, W. L. (2002) The PyMOL Molecular Graphics System, DeLano Scientific LLC, Palo Alto, CA.

12. Morales, R., Charon, M. H., Hudry-Clergeon, G., Pétillot, Y., Norager, S., Medina, M., and Frey, M. (1999) Refined X-ray structures of the oxidized, [2Fe-2S] ferredoxin from the cyanobacterium at $1.17 \AA$ reduced at $1.3 \AA$, and Anabaena PCC7119 show redox-linked conformational changes. Biochemistry 38, 15764-15773.

13. Müller, A., Müller, J. J., Müller, Y. A., Uhlmann, H., Bernhardt, R., and Heinemann, U. (1998) New aspects of electron transfer revealed by the crystal structure of a truncated bovine adrenodoxin, Adx(4-108). Structure 6, 269-280.

14. Beilke, D., Weiss, R., Lohr, F., Pristovsek, P., Hannemann, F., Bernhardt, R., and Ruterjans, H. (2002) A new electron transport mechanism in mitochondrial steroid hydroxylase systems based on structural changes upon the reduction of adrenodoxin. Biochemistry 41, 7969-7978.

15. Sevrioukova, I. F., Garcia, C., Li, H. Y., Bhaskar, B., and Poulos, T. L. J. Mol. Biol. (2003) Crystal structure of putidaredoxin, the $[2 \mathrm{Fe}-2 \mathrm{~S}]$ component of the P-450 $0_{\text {cam }}$ monooxygenase system from Pseudomonas putida. J. Mol. Biol. 333, 377-392.

16. Pizzitutti, F., Sétif, P., and Marchi, M. (2004) Theoretical investigation of the "CO in"-"CO out" isomerization in a [2Fe-2S] ferredoxin: free energy profiles and redox states. J. Am. Chem. Soc. $125,15224-15232$.

17. Shakya, S. K., Gu, W., and Helms, V. (2005) Molecular dynamics simulation of truncated bovine adrenodoxin. Biopolymers 78, 920.

18. Hintz, M. J., Mock, D. M., Peterson, L. L., Tuttle, K., and Peterson, J. A. (1982) Equilibrium and kinetic studies of the interaction of cytochrome $\mathrm{P}-450_{\text {cam }}$ and putidaredoxin. J. Biol. Chem. 257, 1432414332.

19. Pochapsky, T. C., Kostic, M., Jain, N., and Pejchal, R. (2001) Redox-dependent conformational selection in a $\mathrm{Cys}_{4} \mathrm{Fe}_{2} \mathrm{~S}_{2}$ ferredoxin. Biochemistry 40, 5602-5614.

20. Jain, N., and Pochapsky, T. C. (1999) A new assignment strategy for the hyperfine-shifted ${ }^{13} \mathrm{C}$ and ${ }^{15} \mathrm{~N}$ resonances in $\mathrm{Fe}_{2} \mathrm{~S}_{2}$ ferredoxins. Biochem. Biophys. Res. Commun. 258, 54-59.

21. Fu, W., Drozdzewski, P. M., Davies, M. D., Sligar, S. G., and Johnson, M. K. (1992) Resonance Raman and magnetic circular dichroism studies of reduced [2Fe-2S] proteins. J. Biol. Chem. 267, 15502-15510.

22. Han, S., Czernuszewicz, R. S., Kimura, T., Adams, M. W. W., and Spiro, T. G. (1989) $\mathrm{Fe}_{2} \mathrm{~S}_{2}$ protein resonance raman revisited: structural variations among adrenodoxin, red paramagnetic protein ferredoxin. J. Am. Chem. Soc. 111, 3505-3511.

23. Meyer, J., Clay, M. D., Johnson, M. K., Stubna, A., Münck, E., Higgins, C., and Wittung-Stafshede, P. (2002) A hyperthermophilic plant-type $[2 \mathrm{Fe}-2 \mathrm{~S}]$ ferredoxin from Aquifex aeolicus is stabilized by a disulfide bond. Biochemistry 41, 3096-3108.

24. Han, S., Czernuszewicz, R. S., and Spiro, T. G. (1989) Vibrational spectra and normal mode analysis for [2Fe-2S] protein analogues using ${ }^{34} \mathrm{~S},{ }^{54} \mathrm{Fe}$, and ${ }^{2} \mathrm{H}$ substitution: coupling of Fe-S Stretch and S-C-C bending modes. J. Am. Chem. Soc. 111, 3496-3504.

25. Yachandra, V. K., Hare, J., Moura, I., and Spiro, T. G. (1983) Resonance Raman spectra of rubredoxin, desulforedoxin, and the synthetic analogue $\mathrm{Fe}\left(\mathrm{S}_{2}-\mathrm{O}-\mathrm{xyl}\right)_{2}{ }^{-}$: conformational effects. J. Am. Chem. Soc. 105, 6455-6461.

26. Czernuszewicz, R. S., LeGall, J., Moura, I., and Spiro, T. G. (1986) Resonance Raman spectra of rubredoxin: new assignments and vibrational coupling mechanism from Iron-54/Iron-56 isotope shifts and variable wavelength excitation. Inorg. Chem. 26, 696-700.

27. Czernuszewicz, R. S., Kilpatrick, L. K., Koch, S. A., and Spiro, T. G. (1994) Resonance Raman spectroscopy of iron(III) tetrathiolate complexes: implications for the conformation and force field of rubredoxin. J. Am. Chem. Soc. 116, 1134-1141.

28. Fukuyama, K., Ueki, N., Nakamura, H., Tsukihara, T., and Matsubara, H. (1995) Tertiary structure of [2Fe-2S] ferredoxin from Spirulina platensis refined at 2.5 A resolution: structural comparisons of plant-type ferredoxins and an electrostatic potential analysis. J. Biochem. 117, 1017-1023.

29. Sevrioukova, I. F. J. (2005) Redox-dependent structural reorganization in putidaredoxin, a vertebrate-type [2Fe-2S] ferredoxin from Pseudomonas putida. Mol. Biol. 347, 607-621.

30. Vidakovic, M. S., Fraczkiewicz, G., and Germanas, J. P. (1996) Expression and spectroscopic characterization of the hydrogeno- 
somal $[2 \mathrm{Fe}-2 \mathrm{~S}]$ ferredoxin from the protozoan Trichomonas vaginalis. J. Biol. Chem. 271, 14734-14749.

31. Crossnoe, C. R., Germanas, J. P., LeMagueres, P., Mustata, G., and Krause1, K. L. (2002) The crystal structure of Trichomonas vaginalis ferredoxin provides insight into metronidazole activation. J. Mol. Biol. 318, 503-518.

32. Rotsaert, F. A., Pikus, J. D., Fox, B. G., Markley, J. L., and SandersLoehr, J. (2003) N-isotope effects on the Raman spectra of $\mathrm{Fe}_{2} \mathrm{~S}_{2}$ ferredoxin and Rieske ferredoxin: evidence for structural rigidity of metal sites. J. Biol. Inorg. Chem. 8, 318-326.

33. Rypniewski, W. R., Oh, B. H., Markley, J. L., Rayment, I., and Holden, H. M. (1991) Crystallization and structure determination to $2.5 \AA$ resolution of the $[2 \mathrm{Fe}-2 \mathrm{~S}]$ ferredoxin isolated from Anabaena 1710. Biochemistry 30, 4126-4131.

34. Kounosu, A., Li, Z., Cosper, N. J., Shokes, J. E., Scott, R. A., Imai, T., Urushiyama, A., and Iwasaki, T. (2004) Engineering a three-cysteine, one-histidine ligand environment into a new hyperthermophilic Archaeal Rieske-type [2Fe-2S] ferredoxin from Sulfolobus solfataricus. J. Biol. Chem. 279, 12519-12528.

35. Williams, R. J. P. (1978) The conformational mobility of proteins and its functional significance. Biochem. Soc. Trans. 6, 1123-1126.

36. Carlson, Curtis, E. H., Trewhella, J., and Heidorn, D. B. (1988) Differences in the solution structures of oxidized and reduced cytochrome c measured by small-angle X-ray scattering. Biochemistry 27, 1121-1125.

37. Morales, R., Charon, M. H., Kachalova, G., Serre, L., Medina, M., Gomez-Moreno, C., and Frey, M. (2000) A redox-dependent interaction between two electron-transfer partners involved in photosynthesis. EMBO Rep. 1, 271-276.

38. Tezcan, F. A., Kaiser, J. T., Mustafi, D., Walton, M. Y., Howard, J. B., and Rees, D. C. (2005) Nitrogenase complexes: multiple docking sites for a nucleotide switch protein. Science 309, $1377-$ 1380.

39. Johnson, D. C., Dean, D. R., Smith, A. D., and Johnson, M. K. (2005) Structure, function, and formation of biological iron-sulfur clusters. Annu. Rev. Biochem. 74, 247-281.

40. Dos Santos, P. C., Dean, D. R., Hu, Y., and Ribbe, M. W. (2004) Formation and insertion of the nitrogenase iron-molybdenum cofactor. Chem. Rev. 104, 1159-1173.

41. Böck, A., King, P. W., Blokesch, M., and Posewitz, M. C. (2006) Maturation of hydrogenases. Adv. Microb. Physiol. 51, 1-225.

42. Alp, E., Sturhahn, W., Toellner, T. S., Zhao, J., Hu, M., and Brown, D. E. (2002) Vibrational dynamics studies by nuclear resonant inelastic X-Ray scattering. Hyperfine Interact. 144/145, 3-20.

43. Sturhahn, W. (2004) Nuclear resonant spectroscopy. J. Phys.: Condens. Matter 16, S497-S530.

44. Leu, B. M., Zgierski, M. Z., Wyllie, G. R. A., Scheidt, W. R. Sturhahn, W., Alp, E. E., Durbin, S. M., and Sage, J. T. (2004) Quantitative vibrational dynamics of iron in nitrosyl porphyrins. J. Am. Chem. Soc. 126, 4211-4227.

45. Sturhahn, W., Toellner, T. S., Alp, E. E., Zhang, X., Ando, M., Yoda, Y., Kikuta, S., Seto, M., Kimball, C. W., and Dabrowski, B. (1995) Phonon density of states measured by inelastic nuclear resonant scattering. Phys. Rev. Lett. 74, 3832-3835.

46. Sage, J. T., Paxson, C., Wyllie, G. R. A., Sturhahn, W., Durbin, S. M., Champion, P. M., Alp, E. E., and Scheidt, W. R. (2001) Nuclear resonance vibrational spectroscopy of a protein activesite mimic. J. Phys.: Condens. Matter 13, 7707-7722.

47. Sturhahn, W. (2000) CONUSS and PHOENIX: evaluation of nuclear resonant scattering data. Hyperfine Interact. 125, 149-172.

48. Chumakov, A. I., Rüffer, R., Leupold, O., and Sergueev, I. (2003) Insight to dynamics of molecules with nuclear inelastic scattering. Struct. Chem. 14, 109-119.

49. Meyer, J. (1986) High-yield chemical assembly of $[2 \mathrm{Fe}-2 \mathrm{X}](X=$ $\mathrm{S}, \mathrm{Se}$ ) clusters into spinach apoferredoxin: product characterization by resonance Raman spectroscopy. Biochim. Biophys. Acta 871, 243-249.

50. Toellner, T. (2000) Monochromatization of synchrotron radiation for nuclear resonant scattering experiments. Hyperfine Interact. 125, $3-28$.

51. Yoda, Y., Yabashi, M., Izumi, K., Zhang, X. W., Kishimoto, S., Kitao, S., Seto, M., Mitsui, T., Harami, T., Imai, Y., and Kikuta, S. (2001) Nuclear resonant scattering beamline at SPring-8. Nucl. Instrum. Methods A 467, 715-718.

52. Shape Software, http://www.shapesoftware.com/.

53. Dowty, E. (1987) Fully automated microcomputer calculation of vibrational spectra. Phys. Chem. Minerals 14, 67-79.

54. Engeln-Mueller, G., and Uhlig, F. (1996) Numerical Algorithms with $C$, Springer-Verlag, New York.
55. Brooks, B. R., Bruccoleri, R. E., Olafson, B. D., States, D. J., Swaminathan, S., and Karplus, M. (1983) CHARMM: A program for macromolecular energy, minimization, and dynamics calculations. J. Comput. Chem. 4, 187-217.

56. Bruschweiler, R. (1995) Collective protein dynamics and nuclear spin relaxation. J. Chem. Phys. 102, 3396-3403.

57. Tama, F., and Sanejouand, Y.-H. (2001) Conformational changes of proteins arising from normal mode calculations. Protein Eng. $14,1-6$.

58. Meyer, J., Moulis, J.-M., and Lutz, M. (1986) Resonance Raman spectroscopy of $[2 \mathrm{Fe}-2 \mathrm{X}]^{2+}(X=\mathrm{S}, \mathrm{Se})$ clusters in ferredoxins. Biochim. Biophys. Acta 873, 108-118.

59. Atta, M., Lafferty, M. E., Johnson, M. K., Gaillard, J., and Meyer, J. (1998) Heterologous biosynthesis and characterization of the [2Fe-2S]-containing N-terminal domain of Clostridium pasteurianum hydrogenase. Biochemistry 37, 15974-15980.

60. Yachandra, V. K., Hare, J., Gewirth, A., Czernuszewicz, R. S., Kimura, T., Holm, R. H., and Spiro, T. G. (1983) Resonance Raman spectra of spinach ferredoxin and adrenodoxin and of analogue complexes. J. Am. Chem. Soc. 105, 6462-6468.

61. Xiao, Y., Wang, H., George, S. J., Smith, M. C., Adams, M. W. W., Francis, E., Jenney, J., Sturhahn, W., Alp, E. E., Zhao, J., Yoda, Y., Dey, A., Solomon, E. I., and Cramer, S. P. (2005) Normal mode analysis of Pyrococcus furiosus rubredoxin via nuclear resonant vibrational spectroscopy (NRVS) and resonance Raman spectroscopy. J. Am. Chem. Soc. 127, 14596-14606.

62. Smulevich, G., and Spiro, T. (1995) Resonance Raman spectroscopy of metalloproteins. Methods Enzymol. 246, 416-460.

63. Frey, R. A., Werder, R. D., and Günthard, H. H. (1970) Far infrared matrix spectra of iron chlorides $\mathrm{Fe}_{2} \mathrm{Cl}_{6}, \mathrm{FeCl}_{3}, \mathrm{Fe}_{2} \mathrm{Cl}_{4}$, and $\mathrm{FeCl}_{2}$. J. Mol. Spectrosc. 35, 260-284.

64. Smith, M. C., Xiao, Y., Wang, H., George, S. J., Coucovanis, D., Koutmos, M., Sturhahn, W., Alp, E. E., Zhao, J., and Cramer, S. P. (2005) Normal mode analysis of $\left[\mathrm{FeCl}_{4}\right]^{-}$and $\left[\mathrm{Fe}_{2} \mathrm{~S}_{2} \mathrm{Cl}_{4}\right]^{2-}$ via vibrational Mössbauer, Resonance Raman, and FT-IR Spectroscopy. Inorg. Chem. 44, 5562-5570.

65. Shoji, M., Koizumi, K., Taniguchi, T., Kitagawa, Y., Yamanaka, S., Okumura, M., and Yamaguchi, K. (2007) Theory of chemical bonds in metalloenzymes III: full geometry optimization and vibration analysis of ferredoxin-type $[2 \mathrm{Fe}-2 \mathrm{~S}]$ cluster. Int. J. Quantum Chem. 107, 116-133.

66. Spiro, T., and Czernuszewicz, R. S. (1995) Resonance Raman spectroscopy of metalloproteins. Methods Enzymol. 246, 4160460.

67. Czernuszewicz, R. S., Macor, K. A., Johnson, M. K., Gewirth, A., and Spiro, T. G. (1987) Vibrational mode structure and symmetry in proteins and analogues containing $\mathrm{Fe}_{4} \mathrm{~S}_{4}$ clusters: resonance Raman evidence for different degrees of distortion in HiPIP and ferredoxin. J. Am. Chem. Soc. 109, 7178-7187.

68. Tinker: Software Tools for Molecular Design, http://dasher. wustl.edu/tinker/.

69. Qiu, D., Dasgupta, S., III, and Spiro, T. G. (1998) Chromophorein-protein modeling of the structures and resonance Raman spectra for type 1 copper proteins. J. Am. Chem. Soc. 120, 12791-12797.

70. Saito, H., Imai, T., Wakita, K., Urushiyama, A., and Yagi, T. (1991) Resonance Raman active vibrations of rubredoxin. Normal coordinate analysis of a 423-atom model. Bull. Chem. Soc. Jpn. 64, 829-836.

71. Cimei, T., Bizzarri, A. R., Cerullo, G., Silvestri, S. D., and Cannistraroa, S. (2003) Excited state charge-transfer dynamics study of poplar plastocyanin by ultrafast pump-probe spectroscopy and molecular dynamics simulation. Biophys. Chem. 106, 221231.

72. Bizzarri, A. R., Paciaroni, A., Arcangeli, C., and Cannistraro, S. (2001) Low-frequency vibrational modes in proteins: a neutron scattering investigation. Eur. J. Biophys. 30, 443-449.

73. Sage, J. T., Durbin, S. M., Sturhahn, W., Wharton, D. C., Champion, P. M., Hession, P., Sutter, J., and Alp, E. E. (2001) Long-range reactive dynamics in myoglobin. Phys. Rev. Lett. 86, 4966-4969.

74. Doster, W., Cusack, S., and Petry, W. (1989) Dynamical transition of myoglobin revealed by inelastic neutron scattering. Nature 337, 754-756.

75. Cusack, S., and Doster, W. (1990) Temperature dependence of the low frequency dynamics of myoglobin. Measurement of the vibrational frequency distribution by inelastic neutron scattering. Biophys. J. 58, 243-251. 
76. Book, L. D., Arnett, D. C., Hu, H., and Scherer, N. F. (1998) Ultrafast pump-probe studies of excited-state charge-transfer dynamics in blue copper proteins. J. Phys. Chem. A 102, 43504359.

77. Nakashima, S., Nagasawa, Y., Seike, K., Okada, T., Sato, M., and Kohzuma, T. (2000) Coherent dynamics in ultrafast charge-transfer reaction of plastocyanin. Chem. Phys. Lett. 331, 396-402.
78. Iwasaki, T., Kounosu, A., Kollling, D. R. J., Crofts, A. R., Dikanov, S. A., Jin, A., Imai, T., and Urushiyama, A. (2004) Characterization of $\mathrm{pH}$-dependent resonance raman transitions of Archael and bacterial Rieske $[2 \mathrm{Fe}-2 \mathrm{~S}]$ proteins. J. Am. Chem. Soc. 126, 4788-4789.

BI701433M 